\title{
Pricing and Channel Coordination in Online-to-Offline Supply Chain Considering Corporate Environmental Responsibility and Lateral Inventory Transshipment
}

\author{
Bingbing Cao ${ }^{1} \mathbb{D}$, Tianhui You ${ }^{2}$, Chunyi Liu ${ }^{2, *}$ and Jian Zhao ${ }^{2}$ \\ 1 School of Management, Guangzhou University, Guangzhou 510006, China; bbcao_neu@163.com \\ 2 School of Business Administration, Northeastern University, Shenyang 110169, China; \\ thyou@mail.neu.edu.cn (T.Y.); nationalarmy@126.com (J.Z.) \\ * Correspondence: cyliu_neu@163.com; Tel.: +86-24-8368-6769
}

check for

updates

Citation: Cao, B.; You, T.; Liu, C.; Zhao, J. Pricing and Channel Coordination in Online-to-Offline Supply Chain Considering Corporate Environmental Responsibility and Lateral Inventory Transshipment. Mathematics 2021, 9, 2623. https:/ / doi.org/10.3390/math9202623

Academic Editor: Manuel Alberto M. Ferreira

Received: 3 September 2021

Accepted: 14 October 2021

Published: 18 October 2021

Publisher's Note: MDPI stays neutral with regard to jurisdictional claims in published maps and institutional affiliations.

Copyright: (C) 2021 by the authors. Licensee MDPI, Basel, Switzerland. This article is an open access article distributed under the terms and conditions of the Creative Commons Attribution (CC BY) license (https:/ / creativecommons.org/licenses/by/ $4.0 /)$.

\begin{abstract}
In this study, we investigate pricing policy and coordination conditions in an onlineto-offline supply chain considering corporate environmental responsibility and lateral inventory transshipment. First, we provide demand functions to capture effects of price, corporate environmental responsibility level, and preference degree of the consumer to online channel. Then, we build profit functions and develop three joint pricing and corporate environmental responsibilitylevel decision models for centralized decision (Scenario CD), retailer Stackelberg game (Scenario RS), and manufacturer Stackelberg game (Scenario MS). Furthermore, we determine the optimal decision policies by solving developed models, and conduct sensitivity analysis of significant factors. Finally, we use a revenue-sharing contract to realize supply chain coordination and find coordination conditions for Scenario RS and MS, and further show the impacts of revenue-sharing rate and investment cost sensitivity on the conditions using numerical studies. We find that optimal joint decision policies can be affected by significant factors to a varying degree. In certain conditions, the revenue-sharing contract can coordinate online-to-offline supply chains considering corporate environmental responsibility and lateral inventory transshipment. Our study proposes a new decision problem, constructs new joint decision models, determines new optimal joint policies, conducts new coordination analysis, and thus contributes to the research on supply chain operations considering corporate environmental responsibility and lateral inventory transshipment.
\end{abstract}

Keywords: online-to-offline supply chain; corporate environmental responsibility; lateral inventory transshipment; pricing; coordination

\section{Introduction}

Over the past decade, the natural environment has suffered significant environmental degradation [1,2], which has caused high environmental costs [3], climate degeneration [1], and many natural disasters [4,5]. For example, the widespread use of dirty energy, such as coal or petrol, brings heavy carbon emissions, and drastically accelerates global warming, retreats ice sheets, and raises sea levels. Environment protection and sustainable development have drawn increasing attention from supply chain firms, government and consumers $[2,6]$. The International Energy Agency reports that global energy-relevant carbon emissions reach a historic amount of 33.1 gigatons with growing rate $1.7 \%$ in 2018 [7]. To improve the environment and realize carbon neutrality, corporate environmental responsibility has increasingly elicited interest from supply chain firms. For example, to take corporate environmental responsibility and obtain competitive advantages, BYD Auto, Volvo, and BMW develop and sell electric or petrol-electric cars, and Gree produces energy-saving air-conditioners.

In an exploding E-commerce era, consumers trend to require more online channel service. It giants the online retail platforms, such as Amazon, Tmall, and JD.com [8,9]. 
Meanwhile, many offline manufacturers provide online channel service through self-run platforms such as WeChat mini-programs or third-party platforms such as Taobao, JD.com, Amazon, which are experiencing rapid growth $[10,11]$. On this background, a new business model emerges, called online-to-offline [12,13]. Online-to-offline mode refers to a mode that, the manufacturer provides online selling service and forwards orders to the retailer who is nearest to customers, and customers can pick up products from the retailer [13,14]. Many firms adopt online-to-offline mode in their practical operations such as Qumei Furniture, OpenTable, Groupon, Restaurant.com, and Wowo Ltd. [14].

In online-to-offline supply chain, firms usually need lateral inventory transshipment. lateral inventory transshipment refers to sharing or rotating inventories among supply chain firms, and has been studied and adopted in multiple practical operations $[15,16]$. It can reduce the inventory cost and is beneficial to improve the service level of supply chain firms. In an online-to-offline supply chain, the virtual lateral inventory transshipment is adopted since all inventories are stored by the retailer, and the manufacturer uses the inventory of retailer to satisfy online demands by offering a certain online-to-offline service price to the offline retailer [14].

The research gap between theoretical results and practical requirements is that, the online-to-offline supply chain firms need to make decisions on price and coordination in their practical operations considering corporate environmental responsibility and lateral inventory transshipment, and require theoretical results to guide them, but the corresponding data is still lacking.

To bridge the gap between theoretical results and practical requirements, we investigate pricing and coordination problems in an online-to-offline supply chain considering corporate environmental responsibility and lateral inventory transshipment. Specifically, we attempt to address the following three sub-problems:

(1) What are the optimal joint pricing and corporate environmental responsibility-level decision policies with lateral inventory transshipment in an online-to-offline supply chain in centralized and decentralized decisions?

(2) What are the coordination conditions of online-to-offline supply chain with lateral inventory transshipment in decentralized decisions?

(3) What can affect joint decision policies and coordination conditions of online-to-offline supply chain with lateral inventory transshipment, and how?

To answer the above sub-questions, we first analyze the structure and interaction process of an online-to-offline supply chain considering corporate environmental responsibility and lateral inventory transshipment. We then develop the demand functions and profit functions of retailers and manufacturer. Then, we construct and solve the joint pricing and corporate environmental responsibility-level decision models in centralized and decentralized decisions, and conduct the sensitivity analysis of significant parameters on optimal joint decision policies. Furthermore, we conduct the coordination analysis of the online-to-offline supply chain, and explore the effects of significant model parameters and supply chain power structure by numerical studies.

Our study contributes to the research on online-to-offline supply chain operations. Specifically (1), we propose a new pricing and coordination problem in an online-to-offline supply chain considering corporate environmental responsibility and lateral inventory transshipment, and show the interaction process of supply chain members. This extends the research scope of online-to-offline supply chain operations. (2) We construct joint pricing and corporate environmental responsibility-level decision models for centralized decision (Scenario CD), retailer Stackelberg game (Scenario RS), and manufacturer Stackelberg game (Scenario MS) in decentralized decisions, find the joint decision policies, show the impacts of the preference degree of the consumer to the offline channel, online-to-offline service cost, and online-to-offline service price on the optimal joint decision policies for three scenarios. This enriches the research method on the online-to-offline supply chain operations. (3) We find supply chain coordination conditions for Scenarios RS and MS, and show impacts of significant model parameters on the conditions using numerical studies. This enriches 
research content on online-to-offline supply chain coordination. In addition, we provide managerial insights for guiding online-to-offline supply chain firms in practical decisions.

The rest of the paper is organized as follows. Section 2 reviews the relevant literature. Section 3 presents the problem description, notation, and basic assumptions. In Section 4, we construct joint decision models and obtain optimal joint decision policies for three scenarios, and further conduct the sensitivity analysis of significant model parameters. Section 5 gives the coordination analysis for Scenarios RS and MS using a revenue-sharing contract, and finds corresponding coordination conditions. Section 6 shows managerial insights for guiding supply chain firms in their practical decisions. Section 7 concludes the study with further research directions.

\section{Literature Review}

Our study focuses on the pricing and coordination problem in an online-to-offline supply chain considering corporate environmental responsibility and lateral inventory transshipment and is mainly related to the following three streams, i.e., operations management in an online-to-offline supply chain, supply chain operations with corporate environmental responsibility, and supply chain operations with lateral inventory transshipment. It is necessary to point out that there are multiple studies in three fields, and thus it is difficult to exhaust these research results. In our study, we will pay more attentions to most representative or latest literature.

\subsection{Operations Management in Online-to-Offline Supply Chain}

In this stream, the literature mainly focuses on pricing, coordination, psychological, behavioral effects sustainable supply chain, service in the supply chain, and omni-channel operations. For studies on supply chain pricing, for example, Chen et al. [17] focused on pricing decisions for both online and offline channels, and showed the impact of power structure on the retail service supply chain. Zhao et al. [14] studied lateral inventory transshipment problem in an online-to-offline supply chain, and demonstrated that there exists a unique Nash equilibrium. Kong et al. [18] investigated joint pricing and service decision of dual-channel operations in an O2O closed-loop supply chain. He et al. [19] examined online selling mode choice and pricing in $\mathrm{O} 2 \mathrm{O}$ tourism supply chain considering corporate social responsibility. Sarkar et al. [20] investigated joint inventory and pricing policy for an online-to-offline closed-loop supply chain. Zheng et al. [21] investigated how the price cap regulations affect the firms' pricing in an online-to-offline supply chain. $\mathrm{Li}$ et al. [8] focused on pricing and new product design strategies in $\mathrm{O} 2 \mathrm{O}$ supply chain considering the impacts of online consumer reviews. Chai et al. [22] studied pricing strategies for $\mathrm{O} 2 \mathrm{O}$ business model considering service spillover and power structure, and showed the impact of service spillover and power structures on supply chain performance.

For studies on online-to-offline supply chain coordination, for examples, Yu et al. [23] studied ordering decisions and coordination with fairness concerns in the dual-channel supply chain. They found that inventory transshipment strategy can realize coordination under $\mathrm{O} 2 \mathrm{O}$ business model. Pei et al. [9] proposed an innovative coordination mechanism to lessen channel competition and helped enhance the profits of all parties.

For studies on psychological behavioral effects, for examples, He et al. [24] studied supply chain decisions with reference quality effect under the $\mathrm{O} 2 \mathrm{O}$ environment, and showed how firms should incorporate the reference quality effect under different business models. Yan et al. [25] found by analysis that the manufacturer's willingness to employ the marketplace channel increases and the e-tailer's willingness to do so decreases in the level of spillovers. Zend et al. [26] analyzed the effects of government anticipated greening activity on optimal decisions and profit in an online-to-offline closed-loop supply chain. Ma et al. [27] analyzed the impacts of psychological behavioral factors on productservice supply chain decisions in an online-to-offline mode. Ma et al. [28] studied big data empowering low-carbon smart tourism $\mathrm{O} 2 \mathrm{O}$ supply chain considering consumer behaviors 
and corporate altruistic preferences, and showed that altruistic preference can promote sustainable development of low-carbon tourism supply chain.

For studies on sustainable supply chains, for example, Sarkar et al. [29] proposed a sustainable online-to-offline retailing strategy to provide better service to the consumer. Wu et al. [12] investigated low-carbon decision-making problem in an online shopping supply chain considering $\mathrm{O} 2 \mathrm{O}$ model. Wu et al. [13] examined the government-led low-carbon incentive model of the online shopping supply chain considering the $\mathrm{O} 2 \mathrm{O}$ model, and showed that environment cost has not changed if carbon emission is limited by government.

For studies on service in the supply chain, for examples, Sett et al. [30] investigated the effect of $\mathrm{O} 2 \mathrm{O}$ retail service quality in supply chain management, and showed that the vendor will provide lower quality items. Xu et al. [31] focused on the impact of service sharing on decisions in an online-to-offline retail market, and found that service sharing always benefits brand supplier. Sun et al. [32] explored the O2O selection mode portrait and optimization for railway service enterprises based on K-means. They found that optimal mode can be impacted by operating capabilities of the partners.

For the studies on omni-channel operations, for examples, Melacini et al. [33] conducted a systematic literature review on E-fulfilment and distribution in omni-channel retailing. Cai and Lo [34] conducted a systematic review on omni-channel management in new retailing era, and provided managerial applications to retail firms with omnichannel strategy. Jiang et al. [35] focused on pricing decisions for an omni-channel supply chain, and indicated that service value strongly influences players' pricing strategies. Liu et al. [36] studied operation strategies for omni-channel supply chain, and showed which stakeholder benefitted from taking on an online channel and offline service. $\mathrm{Wu}$ et al. [37] investigated integrated randomized pricing strategy for omni-channel retailing. $\mathrm{Li}$ et al. [38] focused on cooperative advertising and pricing problem in $\mathrm{O} 2 \mathrm{O}$ supply chain with buy-online-and-pick-up-in-store (BOPS), and found that the implementation of BOPS can partially substitute the incentive effect of cooperative advertising. In addition, some scholars also explored supply chain cooperation [39], channel choice [40], and supply chain management networks [41].

\subsection{Supply Chain Operations with Corporate Environmental Responsibility}

In this stream, the literature mainly focuses on pricing, contract design, strategy choice, and supply chain environmental performance. For studies on supply chain pricing with corporate environmental responsibility, for example, Wen et al. [42] explored price and collection rate decisions in a closed-loop supply chain with environmental responsibility, and indicated that collection rate under equal-pricing mode may be higher than that under differentiated pricing mode. Wu et al. [3] developed closed-loop supply chain models for joint environmental responsibility investment, recycling and pricing decisions, and found recycling strategy of third-party-led collection is disadvantageous. Yuan et al. [43] investigated green remanufacturer's mixed collection channel strategy considering enterprise's environmental responsibility and fairness concern, and showed the impact of environmental responsibility on optimal decision.

For studies on supply chain coordination with corporate environmental responsibility, for examples, Hong and Guo [44] designed several cooperation contracts in green supply chain and investigated their environmental performance. Heydari and Rafiei [45] studied sustainable supply chain coordination considering consumers' environmental and social awareness, and designed a contract to coordinate the supply chain. Xia and Niu [7] designed a carbon-reducing contract for a supply chain with environmental responsibility, and showed that optimal contract ensures profitability and compliance with environmental responsibilities. Xie et al. [46] analyzed supply chain coordination considering the impacts of uncertain yield and demand. Heydari et al. [47] proposed a green supply chain coordination approach to balance price and green quality in the presence of consumer environmental awareness. 
For studies on strategy choice in the supply chain with corporate environmental responsibility, for examples, Lee et al. [48] examined antecedents of organizational commitment for adopting corporate environmental responsibility and green practices. Yang et al. [49] focused on dual-channel structure choice of an environmental responsibility supply chain, and found that the retailer may benefit from the introduction of direct channel when green costs are relatively low. Wu et al. [50] focused on supply chain structure under horizontal chain-to-chain competition, and proposed the optimal supply chain structural choice policy.

For studies on supply chain environmental performance, for example, Carbone et al. [51] investigated to what extent the dynamic capabilities developed in green supply chain management can foster social supply chain performance. Qin et al. [52] found that corporate environmental responsibility practice will help correct environmental externalities and further contribute to the implementation of national environmental plans. Kraus et al. [1] investigated the influence of corporate social responsibility on environmental performance, and showed the mediating role of environmental strategy and green innovation. In addition, some scholars also focused on supplier evasion of a buyer's audit [53], SME [6,54], global value chain [55], corporate boundaries [56], specific supply chain $[2,57]$. For more reviews on management theories related to environmental and social responsibility, we refer interested readers to the literature [58].

\subsection{Supply Chain Operations with Lateral Inventory Transshipment}

In this stream, the literature mainly focuses on multi-location or multi-sourcing inventory management, and specific products inventory management. For the studies on multilocation or multi-sourcing inventory management, for example, Herer and Rashit [59] addressed a two-location inventory system with lateral stock transshipments, and discussed the single-period planning horizon. Firouz et al. [60] studied the integrated supplier selection and inventory problem with multi-sourcing and lateral transshipments, and found that inferior decisions may result. Nakandala et al. [15] investigated the scenario of sourcing goods through lateral transshipments, and proposed a two-step decision rule. Meissner and Senicheva [61] conducted approximate dynamic programming for lateral transshipment problems in multi-location inventory systems, and obtained an optimal policy.

For the studies on specific product inventory management types, for example, the Grahovac and Chakravarty [62] studied sharing and lateral transshipment of inventory in a supply chain with expensive, low-demand items. Nakandala et al. [16] focused on lateral transshipment problem for perishable inventory management. Shokouhifar et al. [63] developed an inventory management model for blood supply chains with lateral transshipment. Additionally, some scholars studied inventory management with lateral transshipment from perspectives of risk [64], service [65], and E-commerce platform [14]. For more detailed research reviews before 2011, we refer interested readers to review the literature [66].

To better position our study in the extant literature, we compare the closely related literature with our study in Table 1 with respect to the following key features, i.e., onlineto-offline supply chain, pricing, coordination, corporate environmental responsibility, and lateral inventory transshipment. 
Table 1. The comparison between our study and closely related literature.

\begin{tabular}{lccccc}
\hline References & $\begin{array}{c}\text { Online-to-Offline } \\
\text { Supply Chain }\end{array}$ & Pricing & Coordination & $\begin{array}{c}\text { Corporate Environmental } \\
\text { Responsibility }\end{array}$ & $\begin{array}{c}\text { Lateral Inventory } \\
\text { Transshipment }\end{array}$ \\
\hline Zhao et al. [14] & $\sqrt{ }$ & & & \\
Sarkar et al. [20] & $\sqrt{ }$ & $\sqrt{ }$ & & \\
Chai et al. [22] & $\sqrt{ }$ & $\sqrt{ }$ & & \\
Yu et al. [23] & $\sqrt{ }$ & $\sqrt{ }$ & & $\sqrt{ }$ \\
Jiang et al. [35] & & $\sqrt{ }$ & $\sqrt{ }$ & \\
Wen et al. [42] & & & $\sqrt{ }$ & $\sqrt{ }$ \\
Yuan et al. [43] & & $\sqrt{ }$ & $\sqrt{ }$ \\
Yang et al. [49] & $\sqrt{ }$ & & & $\sqrt{ }$ \\
Shokouhifar et al. [63] & Our study & & & & \\
\hline
\end{tabular}

It is necessary to point out that, the key reference literatures in our study are [14] and [23]. Our study has essential difference from them, i.e., our study considers corporate environmental responsibility, and pays attention to the decision on the corporate environmental responsibility level.

To summarize, the existing research results on above three streams have made great contributions to the development of supply chain operations, and provide reference and theoretical support to our study. However, these results do not involve pricing and coordination problems in an online-to-offline supply chain considering simultaneously corporate environmental responsibility and lateral inventory transshipment, and thus cannot be suitable to solve the problem in our study. Given the environment requirement of government, consumers, and firm practice, we plan to bridge the gap between theoretical research and practice in our study.

\section{Problem Description, Notation, and Basic Assumptions}

\subsection{Problem Description}

We consider an online-to-offline dual-channel supply chain consisting of one manufacturer and one retailer; the manufacturer produces with corporate environmental responsibility, and sells the product through the retailer in the offline channel and its self-operated E-store in an online channel. The retailer stores all inventories. For offline channel, the retailer first orders from the manufacturer, the manufacturer makes the product according to the order and the demand in an online channel, and delivers the product to the retailer before the selling season. At the beginning of the selling season, the retailer sells the product to the offline market, and the manufacturer sells the product to the online market through a self-operated E-store. It is necessary to note that the manufacturer requires the online-to-offline service of retailer with lateral inventory transshipment. Specifically, the manufacturer forwards orders to the retailer if the manufacturer receives orders from online channel, then the retailer will provide the online-to-offline service with lateral inventory transshipment by certain service prices and costs. Consumers can pick up products from the retailer. The structure and interaction process of supply chain firms can be seen in detail in Figure 1.

We focus the study on joint pricing and corporate environmental responsibility-level decisions and supply chain coordination, and further consider the following three decision scenarios.

Scenario CD: The centralized decision with manufacturer's corporate environmental responsibility and lateral inventory transshipment in an online-to-offline dual-channel supply chain.

Scenario RS: The retailer Stackelberg game in a decentralized decision with manufacturer's corporate environmental responsibility and lateral inventory transshipment in an online-to-offline dual-channel supply chain.

Scenario MS: The manufacturer Stackelberg game in decentralized decision with manufacturer's corporate environmental responsibility and lateral inventory transshipment in an online-to-offline dual-channel supply chain. 


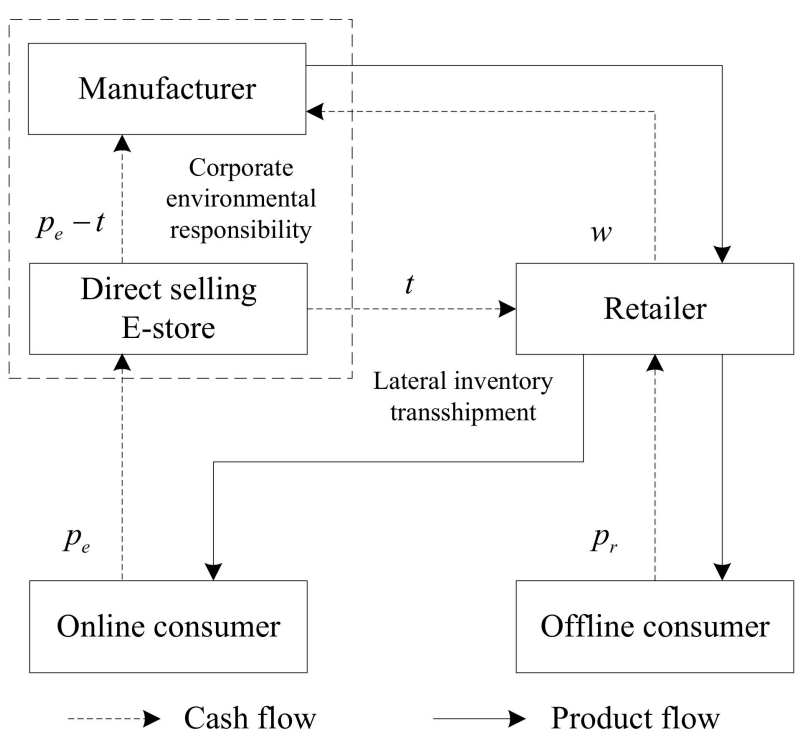

Figure 1. The structure and interaction process of online-to-offline supply chain.

In the problem, the manufacturer needs to decide the corporate environmental responsibility level, retail price in an online channel, and wholesale price in an offline channel. The retailer must decide margin price in the offline channel. To solve the problem, we need to pay attention to the following sub-problems:

(1) How to build demand functions and profit functions of online-to-offline supply chain firms considering manufacturer's corporate environmental responsibility and lateral inventory transshipment.

(2) How to construct the joint pricing and corporate environmental responsibility-level decision models for three decision scenarios.

(3) How to coordinate online-to-offline supply chain in retailer and manufacturer Stackelberg games.

(4) How do model parameters affect optimal policies of supply chain for three decision scenarios and coordination conditions in retailer and manufacturer Stackelberg games?

\subsection{Notation and Basic Assumptions}

To clearly present the study on pricing policy and coordination analysis in an onlineto-offline supply chain considering manufacturer's corporate environmental responsibility and lateral inventory transshipment, we intensively illustrate the notation of many previously used mathematical symbols for decision variables, parameters, and functions in Table 2. It is necessary to point out that some superscript symbols are used, where superscript $C D$ denotes centralized decision, superscript $R S$ or $M S$ denotes retailer or manufacturer Stackelberg game in decentralized decision, superscript $R C$ or $M C$ denotes contract coordination analysis in retailer or manufacturer Stackelberg game, and superscript $*$ denotes the optimal value. 
Table 2. Notations.

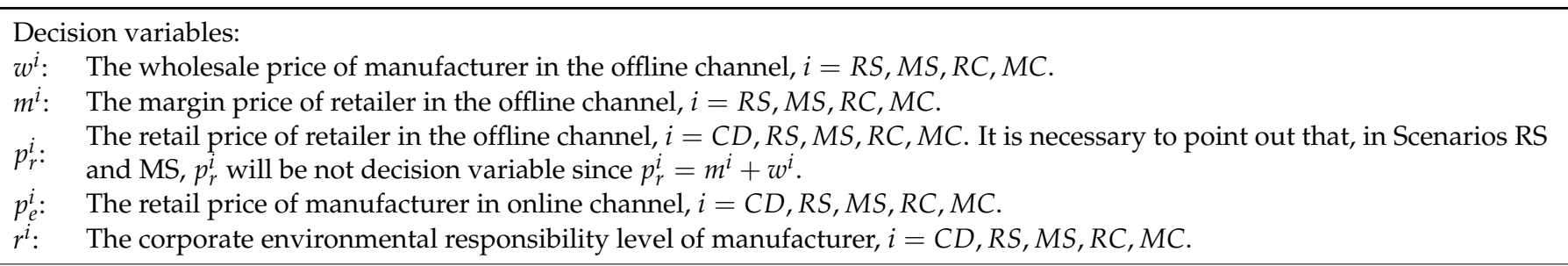

Parameters:

$a$ : The market size, $a>0$.

$\alpha: \quad$ The preference degree of the consumer to the offline channel in purchasing decision, $0<\alpha<1$.

$b_{1}$ : The self-price elasticity, it is used to describe the impact of unit change of retail price on demand in current channel, $b_{1}>0$.

$b_{2}$ : The cross-price elasticity, it is used to describe the impact of unit change of retail price in a competitive channel on demand in

$b_{2}$ : current channel, $0<b_{2}<b_{1}$.

$t$ : The online-to-offline service price of retailer, it is paid by the manufacturer to the retailer for unit product in online-to-offline

mode with lateral inventory transshipment, $t>0$.

l: The online-to-offline service cost of retailer. The retailer needs to bear it for unit product in an online-to-offline mode with

l: $\quad$ lateral inventory transshipment, $0<l<t$.

$c$ : $\quad$ The unit production cost of manufacturer, $c>0$.

The corporate environmental responsibility sensitivity, it is used to describe the impact of unit change of corporate

$k_{x}$ : environmental responsibility level on market demand in the offline or online channel, where $x=r, e$ denotes offline or online channel, respectively, $k_{x}>0$.

$\beta$ : The investment cost sensitivity to corporate environmental responsibility, it is used to describe the impact of unit corporate

$\beta: \quad$ environmental responsibility level on the profit of manufacturer, $\beta>0$.

$\lambda$ : $\quad$ The revenue sharing rate for Scenario RS in coordination analysis, $\lambda>0$.

$\gamma: \quad$ The revenue sharing rate for Scenario MS in coordination analysis, $\gamma>0$.

\footnotetext{
Functions:

$D_{x}$ : The demand function of offline or online channel, $x=r, e$.

$\pi_{j}$ : The profit function of retailer, manufacturer, or supply chain, $j=R, M, S C$.
}

Without loss of generality, we summarize the necessary basic Assumptions 1-5 in our study below:

Assumption 1. The products sold in the offline and online channels have no difference in quality, function, and appearance, and the manufacturer sells the product through online-to-offline mode, and the retailer can provide the online-to-offline service with lateral inventory transshipment [30].

Assumption 2. The price $p_{e}$ in the online channel is greater than wholesale price $w$ in the offline channel, i.e., $p_{e}>w$, and it is also greater than the sum of production cost $c$ and online-tooffline service price $t$, i.e., $p_{e}-c>t$. It indicates that the manufacturer can benefit from the online-to-offline service.

Assumption 3. The online-to-offline service price $t$ is greater than online-to-offline service cost $l$, i.e., $t>l$. It ensures that the retailer can benefit from online-to-offline mode, and will provide online-to-offline service.

Assumption 4. To ensure that the objective functions are concave in the centralized and decentralized decisions, i.e., there is the uniquely optimal policy, we assume $\beta>\beta_{1}=$ $\left[b_{1}\left(k_{e}^{2}+k_{r}^{2}\right)+2 b_{2} k_{e} k_{r}\right] /\left[2\left(b_{1}^{2}-b_{2}^{2}\right)\right]$ by referring to $[67,68]$.

Assumption 5. We consider online-to-offline supply chain firms are in Stackelberg game. In Nash game, supply chain firms have same decision power, but in Stackelberg game, supply chain firms have different decision powers. Since online-to-offline supply chain firms tend to have different decision powers in reality, so we use Stackelberg game in our study [69].

\section{Models and Equilibrium Results}

In this section, we first build demand functions and profit functions considering manufacturer's corporate environmental responsibility and lateral inventory transship- 
ment. Then, for each scenario, we construct the joint pricing and corporate environmental responsibility-level decision models, and conduct the analysis of equilibrium policy and impacts of significant model parameters. To clearly illustrate the analysis structures in three scenarios, we provide frameworks for each scenario:

For Scenario CD, the framework contains Model A, Theorem 1, Propositions 1 and 2, and Table 3 for indicating the impact trends of parameters in Propositions 1 and 2.

For Scenario RS, the framework contains Model B, Theorem 2, Propositions 3-5, and Table 4 for indicating the impact trends of parameters in Propositions 3-5.

For Scenario MS, the framework contains Model C, Theorem 4, Propositions 6-8, and Table 5 for indicating the impact trends of parameters in Propositions 6-8.

\subsection{Demand and Profit Functions}

Generally, the market demand is sensitive to the prices in two channels and corporate environmental responsibility level [70-74]. The linear function is commonly used to describe the price or green sensitive market demand in the supply chain [73,75-79]. Here, we follow them to use linear demand function. Specifically, we consider that the market demand is a monotonously decreasing function with respect to the price but a monotonously increasing function with respect to the price in competitive channel and manufacturer's corporate environmental responsibility level. On this basis, we give the demand functions for offline and online channels below.

$$
\begin{gathered}
D_{r}=\alpha a-b_{1} p_{r}+b_{2} p_{e}+k_{r} r \\
D_{e}=(1-\alpha) a-b_{1} p_{e}+b_{2} p_{r}+k_{e} r
\end{gathered}
$$

Given that the manufacturer's corporate environmental responsibility level will directly affect consumer purchasing decision in an online direct-selling channel, and indirectly affect consumer purchasing decisions in the offline channel through the retailer, so we consider the corporate environmental responsibility sensitivity in the online channel is greater than the one in the offline channel, i.e., $k_{e}>k_{r}>0$. To ensure that supply chain firms can benefit from the offline channel, we also consider $a-b_{1} c>0$.

The corporate environmental responsibility level can increase the demand, but will lead the manufacturer to bear the additional cost, i.e., the investment cost of the corporate environmental responsibility. According to the existing literature [80,81], we adopt a commonly used quadratic function to describe the investment cost of the corporate environmental responsibility. Specifically, for the corporate environmental responsibility level $r$, the manufacturer's investment cost is $\beta r^{2} / 2$.

Furthermore, we can build profit functions of retailer and manufacturer in the supply chain, i.e.,

$$
\begin{gathered}
\pi_{R}=\left(p_{r}-w\right) D_{r}+(t-l) D_{e} \\
\pi_{M}=(w-c) D_{r}+\left(p_{e}-c-t\right) D_{e}-\beta r^{2} / 2
\end{gathered}
$$

\subsection{Scenario $C D$}

In Scenario CD, the manufacturer and retailer are integrated vertically, and attempt to find a joint pricing and corporate environmental responsibility-level decision policy to maximize the profit of supply chain. According to Equations (3) and (4), we can obtain the profit of supply chain, and can further construct the joint pricing and corporate environmental responsibility-level decision model for Scenario CD, i.e., Model A.

Model A: $\max _{p_{r}, p_{e}, r} \pi_{S C}=\pi_{R}+\pi_{M}=\left(p_{r}-c\right) D_{r}+\left(p_{e}-c-l\right) D_{e}-\beta r^{2} / 2$

By solving Model A, we can obtain following theoretical results. 
Theorem 1. In Scenario $C D$, there is uniquely optimal joint decision policy of retail prices $p_{r}^{C D *}$ and $p_{e}^{C D *}$, and corporate environmental responsibility level $r^{C D *}$, i.e.,

$$
\begin{gathered}
p_{r}^{C D *}=\frac{\left\{\begin{array}{l}
\left(k_{e}^{2}-2 \beta b_{1}\right) \alpha a-\left(b_{2}+k_{r} k_{e}\right)(1-\alpha) a-2 \beta\left(b_{1}^{2}-b_{2}^{2}\right) c+\left(2 b_{1}+b_{2}\right) c k_{e}^{2} \\
+\left(b_{1}+3 b_{2}\right) c k_{r} k_{e}+k_{e} l\left(b_{1} k_{r}+b_{2} k_{e}\right)
\end{array}\right\}}{2\left[b_{1}\left(k_{e}^{2}+k_{r}^{2}\right)+2 b_{2} k_{e} k_{r}-2 \beta\left(b_{1}^{2}-b_{2}^{2}\right)\right]} \\
p_{e}^{C D *}=\frac{\left\{\begin{array}{l}
\left(k_{r}^{2}-2 \beta b_{1}\right)(1-\alpha) a-\left(k_{r} k_{e}+2 \beta b_{2}\right) \alpha a-2 \beta\left(b_{1}^{2}-b_{2}^{2}\right)(c+c l)+\left(b_{1}+b_{2}\right) c k_{r}^{2} \\
+2 b_{1} c k_{e}^{2}+\left(b_{1}+3 b_{2}\right) c k_{r} k_{e}+l\left(b_{1} k_{r}^{2}+2 b_{1} k_{e}^{2}+3 b_{2} k_{r} k_{k}\right)
\end{array}\right\}}{2\left[b_{1}\left(k_{e}^{2}+k_{r}^{2}\right)+2 b_{2} k_{e} k_{r}-2 \beta\left(b_{1}^{2}-b_{2}^{2}\right)\right]} \\
r^{C D *}=\frac{\left(b_{1}^{2}-b_{2}^{2}\right)\left[c\left(k_{r}+k_{e}\right)+k_{e} l\right]-\left(b_{1} k_{r}+b_{2} k_{e}\right) \alpha a-\left(b_{1} k_{e}+b_{2} k_{r}\right)(1-\alpha) a}{b_{1}\left(k_{e}^{2}+k_{r}^{2}\right)+2 b_{2} k_{e} k_{r}-2 \beta\left(b_{1}^{2}-b_{2}^{2}\right)}
\end{gathered}
$$

The proof can be seen in Appendix A.

Proposition 1. In Scenario $C D$, the optimal joint decision policy of $p_{r}^{C D *}, p_{e}^{C D *}$, and $r^{C D *}$ is sensitive to preference degree $\alpha$ of the consumer to the offline channel. Specifically,

(1) Price $p_{r}^{C D *}$ in the offline channel decreases with degree $\alpha$ if $\beta_{1}<\beta \leq \beta_{c d 1}$, but increases with degree $\alpha$ if $\beta>\beta_{c d 1}$.

(2) Price $p_{e}^{C D *}$ in the online channel decreases with degree $\alpha$.

(3) Corporate environmental responsibility level $r^{C D *}$ decreases with degree $\alpha$. where $\beta_{c d 1}=$ $k_{e}\left(k_{r}+k_{e}\right) /\left[2\left(b_{1}-b_{2}\right)\right]$.

The proof can be seen in Appendix A.

Proposition 2. In Scenario $C D$, the optimal joint decision policy of $p_{r}^{C D *}, p_{e}^{C D *}$, and $r^{C D *}$ is sensitive to online-to-offline service costlof retailer. Specifically,

(1) Price $p_{r}^{C D *}$ in the offline channel decreases with the online-to-offline service cost $l$.

(2) Price $p_{e}^{C D *}$ in the online channel decreases with the online-to-offline service cost l if $\beta_{1}<$ $\beta \leq \beta_{c d 2}$, but increases with the online-to-offline service cost $l$ if $\beta>\beta_{c d 2}$.

(3) Corporate environmental responsibility level $r^{C D *}$ decreases with the online-to-offline service cost l. where $\beta_{c d 2}=\left[b_{1}\left(2 k_{e}^{2}+k_{r}^{2}\right)+3 b_{2} k_{e} k_{r}\right] /\left[2\left(b_{1}^{2}-b_{2}^{2}\right)\right]$.

The proof can be seen in Appendix A.

According to Propositions 1 and 2, we can summarize impact trends of model parameters in Scenario CD in Table 3.

Table 3. The sensitivities of optimal policy to model parameters in Scenario CD.

\begin{tabular}{cccc}
\hline & $\alpha$ & $l$ & $t$ \\
\hline$p_{r}^{C D *}$ & $\downarrow \uparrow$ & $\downarrow$ & - \\
$p_{e}^{C D *}$ & $\downarrow$ & $\downarrow \uparrow$ & - \\
$r^{C D *}$ & $\downarrow$ & $\downarrow$ & - \\
\hline
\end{tabular}

Notes: $\uparrow:$ increase; $\downarrow$ : decrease; -: unchanged.

For impact trends of degree $\alpha$ in Table 3, the reason is that, increasing $\alpha$ will reduce the demand in the online channel, supply chain needs to decrease price $p_{e}^{C D *}$ to keep online orders, it will lead to profit loss in the online channel; to make up the loss, supply chain needs to reduce the cost, so level $r^{C D *}$ decreases. For price $p_{r}^{C D *}$, it may decrease or increase. For increasing $\alpha$, the profit in the offline channel increases, but the profit change of whole supply chain may not be certain since the profit in the online channel decreases. For lower $\beta$, both online and offline channels can contribute to the profit of supply chain, so supply chain will decrease price $p_{r}^{C D *}$ to realize the profits equilibrium for both channels. 
However, for higher $\beta$, the profit of supply chain will be mainly from offline channel, so the supply chain will increase $p_{r}^{C D *}$ to obtain more profits.

For impact trends of cost $l$ in Table 3 , the reason is that increasing $l$ will increase the cost and further reduce the profit of supply chain, so supply chain will decrease price $p_{r}^{C D *}$ to reduce the demand in the online channel to avoid additional cost loss; to make up the loss, supply chain still needs to decrease level $r^{C D *}$. For price $p_{e}^{C D *}$, it may also decrease or increase. Similarly, for lower $\beta$, both online and offline channels can also contribute to the profit of supply chain, so supply chain will decrease price $p_{e}^{C D *}$ to incentivize more online consumers to purchase the product. However, for higher $\beta$, the profit of supply chain will be mainly from offline channel, so the supply chain will increase $p_{e}^{C D *}$ to improve the demand in the offline channel and seek for more profits.

In addition, the optimal policy is not related to service price $t$ in the centralized supply chain.

\subsection{Scenario $R S$}

In scenario RS, the retailer is the leader in an online-to-offline supply chain. According to Stackelberg game and Equations (3) and (4), we can construct the joint pricing and corporate environmental responsibility-level decision model for Scenario RS, i.e., Model B.

$\max _{m} \pi_{R}\left(m \mid p_{e}, r, w\right)=\left(p_{r}-w\right) D_{r}+(t-l) D_{e}$
Model B: $\quad \begin{aligned} & p_{e}{ }^{*}, r^{*}, w^{*} \in \operatorname{argmax} \pi_{M}\left(p_{e}, r, w \mid m\right)=(w-c) D_{r}+\left(p_{e}-c-t\right) D_{e}-\frac{\beta r^{2}}{2} \\ & p_{r}=m+w\end{aligned}$

By solving Model B, we can obtain following theoretical results.

Theorem 2. In Scenario RS, there is uniquely optimal joint decision policy of margin price $m^{R S *}$, wholesale price $w^{R S *}$, online retail price $p_{e}^{R S *}$, and corporate environmental responsibility level $r^{R S *}$, i.e.,

$$
\begin{gathered}
m^{R S *}=\frac{\left\{\begin{array}{l}
2 \alpha \beta a\left(b_{1}^{2}-b_{2}^{2}\right)-a\left(b_{1} k_{e}+b_{2} k_{r}\right)\left[\alpha k_{e}-(1-\alpha) k_{r}\right] \\
\left.+(c-l+2 t)\left[2 \beta b_{2}\left(b_{1}^{2}-b_{2}^{2}\right)-k_{e} k_{r}\left(b_{1}^{2}+b_{2}^{2}\right)-b_{1} b_{2}\left(k_{e}^{2}+k_{r}^{2}\right)\right]\right\}
\end{array}-c\right.}{2\left[2 \beta b_{1}\left(b_{1}^{2}-b_{2}^{2}\right)-\left(b_{1} k_{e}+b_{2} k_{r}\right)^{2}\right]}-\begin{array}{c}
+\frac{c-m^{R S *}}{2} \\
w^{R S *}=\frac{a k_{e}\left[\alpha k_{e}-(1-\alpha) k_{r}\right]+\left(b_{1} k_{r}+b_{2} k_{e}\right)\left[(c+t) k_{e}+\left(c+m^{R S *}\right) k_{r}\right]-2 a \beta\left[b_{2}(1-\alpha)+b_{1} \alpha\right]}{2\left[b_{1}\left(k_{e}^{2}+k_{r}^{2}\right)-2 \beta\left(b_{1}^{2}-b_{2}^{2}\right)+2 b_{2} k_{e} k_{r}\right]} \\
p_{e}^{R S *}=\frac{\left\{\begin{array}{l}
2 \alpha \beta a\left(b_{1}^{2}-b_{2}^{2}\right)-a\left(b_{1} k_{e}+b_{2} k_{r}\right)\left[\alpha k_{e}-(1-\alpha) k_{r}\right] \\
+(c-l+2 t)\left[2 \beta b_{2}\left(b_{1}^{2}-b_{2}^{2}\right)-k_{e} k_{r}\left(b_{1}^{2}+b_{2}^{2}\right)-b_{1} b_{2}\left(k_{e}^{2}+k_{r}^{2}\right)\right]
\end{array}\right\}}{4\left[2 \beta b_{1}\left(b_{1}^{2}-b_{2}^{2}\right)-\left(b_{1} k_{e}+b_{2} k_{r}\right)^{2}\right]\left[b_{1}\left(k_{e}^{2}+k_{r}^{2}\right)-2 \beta\left(b_{1}^{2}-b_{2}^{2}\right)+2 b_{2} k_{e} k_{r}\right]}+\frac{c+t}{2} \\
r^{R S *}=\frac{\left(b_{1}^{2}+b_{2}^{2}\right)\left[(c+t) k_{e}+\left(c+m^{R S *}\right) k_{r}\right]+a(1-\alpha)\left(b_{2} k_{r}-b_{1} k_{e}\right)-a \alpha\left(b_{1} k_{r}+b_{2} k_{e}\right)}{b_{1}\left(k_{e}^{2}+k_{r}^{2}\right)-2 \beta\left(b_{1}^{2}-b_{2}^{2}\right)+2 b_{2} k_{e} k_{r}}
\end{array}
\end{gathered}
$$

The proof can be seen in Appendix A.

Furthermore, we can obtain optimal retail price $p_{r}^{R S *}$ in the offline channel according to Equations (8) and (9), i.e.,

$$
\begin{aligned}
p_{r}^{R S *} & =\frac{a k_{e}\left[\alpha k_{e}-(1-\alpha) k_{r}\right]+\left(b_{1} k_{r}+b_{2} k_{e}\right)\left[(c+t) k_{e}+(c+m) k_{r}\right]-2 a \beta\left[b_{2}(1-\alpha)+b_{1} \alpha\right]}{2\left[b_{1}\left(k_{e}^{2}+k_{r}^{2}\right)-2 \beta\left(b_{1}^{2}-b_{2}^{2}\right)+2 b_{2} k_{e} k_{r}\right]} \\
& +\frac{c+m^{R S *}}{2}
\end{aligned}
$$

Proposition 3. In Scenario RS, the optimal joint decision policy of $m^{R S *}, w^{R S *}, p_{r}^{R S *}, p_{e}^{R S *}$, and $r^{R S *}$ is sensitive to preference degree $\alpha$ of the consumer to the offline channel. Specifically,

(1) Margin price $m^{R S *}$ in the offline channel decreases with degree $\alpha$ if $\beta_{1}<\beta \leq \beta_{m r s}$, but increases with degree $\alpha$ if $\beta>\beta_{m r s 1}$. 
(2) Wholesale price $w^{R S *}$ in the offline channel decreases with degree $\alpha$ if $Y_{w \alpha 1} \leq 0$, but increases with degree $\alpha$ if $Y_{w \alpha 1}>0$.

(3) Retail price $p_{r}^{R S *}$ in the offline channel decreases with degree $\alpha$ if $Y_{\text {pr } \alpha 1} \leq 0$, but increases with degree $\alpha$ if $Y_{\text {pr } \alpha 1}>0$.

(4) Retail price $p_{e}^{R S *}$ in the online channel decreases with degree $\alpha$.

(5) Corporate environmental responsibility level $r^{R S *}$ decreases with degree $\alpha$.

$$
\begin{aligned}
& \text { where } \beta_{\text {mrs } 1}=\left(b_{1} k_{e}+b_{2} k_{r}\right)\left(k_{e}+k_{r}\right) /\left[2\left(b_{1}^{2}-b_{2}^{2}\right)\right] \\
& \qquad \begin{aligned}
Y_{w \alpha 1} & =2 \beta b_{2}\left(b_{1}-b_{2}\right)\left[b_{1}\left(k_{e}^{2}+k_{r}^{2}\right)+2 b_{2} k_{e} k_{r}-2 \beta\left(b_{1}^{2}-b_{2}^{2}\right)\right] \\
& +\left[k_{e}\left(k_{e}+k_{r}\right)-2 \beta\left(b_{1}-b_{2}\right)\right]\left[\left(b_{1} k_{e}+b_{2} k_{r}\right)^{2}-2 \beta b_{1}\left(b_{1}^{2}-b_{2}^{2}\right)\right], \\
Y_{p r \alpha 1} & =2\left[b_{1}\left(k_{e}^{2}+k_{r}^{2}\right)+2 b_{2} k_{e} k_{r}-2 \beta\left(b_{1}^{2}-b_{2}^{2}\right)\right]\left[\left(b_{1} k_{e}+b_{2} k_{r}\right)\left(k_{e}+k_{r}\right)-\beta\left(b_{1}-b_{2}\right)\left(2 b_{1}+b_{2}\right)\right] \\
& +\left[k_{e}\left(k_{e}+k_{r}\right)-2 \beta\left(b_{1}-b_{2}\right)\right]\left[\left(b_{1} k_{e}+b_{2} k_{r}\right)^{2}-2 \beta b_{1}\left(b_{1}^{2}-b_{2}^{2}\right)\right] .
\end{aligned}
\end{aligned}
$$

The proof can be seen in Appendix A.

Proposition 4. In Scenario $R S$, the optimal joint decision policy of $m^{R S *}, w^{R S *}, p_{r}^{R S *}, p_{e}^{R S *}$, and $r^{R S *}$ is sensitive to online-to-offline service cost 1 of retailer. Specifically,

(1) Margin price $m^{R S *}$ in the offline channel increases with the online-to-offline service cost $l$ if $\beta_{1}<\beta \leq \beta_{r s}$, but decreases with the online-to-offline service cost l if $\beta>\beta_{r s}$.

(2) Wholesale price $w^{R S *}$ in the offline channel decreases with the online-to-offline service cost $l$ if $\beta_{1}<\beta \leq \beta_{r s}$, but increases with the online-to-offline service cost l if $\beta>\beta_{r s}$.

(3) Retail price $p_{r}^{R S *}$ in the offline channel decreases with the online-to-offline service cost $l$ if $\beta_{1}<\beta \leq \min \left\{\beta_{r s}, \beta_{\text {prrs }}\right\}$ or $\beta>\max \left\{\beta_{r s}, \beta_{\text {prrs }}\right\}$, but increases with the online-to-offline service cost $l$ if $\beta_{r s}<\beta \leq \beta_{\text {prrs }}$ or $\beta_{\text {prrs }}<\beta \leq \beta_{\text {rs }}$.

(4) Retail price $p_{e}^{R S *}$ in the online channel decreases with the online-to-offline service cost $l$ if $\beta_{1}<\beta<\beta_{r s}$, but increases with the online-to-offline service cost l if $\beta>\beta_{r s}$.

(5) Corporate environmental responsibility level $r^{R S *}$ decreases with the online-to-offline service cost $l$ if $\beta_{1}<\beta<\beta_{r s}$, but increases with the online-to-offline service cost $l$ if $\beta>\beta_{r s}$. where $\beta_{r s}=\left[k_{e} k_{r}\left(b_{1}^{2}+b_{2}^{2}\right)+b_{1} b_{2}\left(k_{e}^{2}+k_{r}^{2}\right)\right] /\left[2 b_{2}\left(b_{1}^{2}-b_{2}^{2}\right)\right]$, $\beta_{\text {prrs }}=\left(b_{1} k_{e}^{2}+3 b_{2} k_{e} k_{r}+2 b_{1} k_{r}^{2}\right) /\left[2\left(b_{1}^{2}-b_{2}^{2}\right)\right]$.

The proof can be seen in Appendix A.

Proposition 5. In Scenario RS, the optimal joint decision policy of $m^{R S *}, w^{R S *}, p_{r}^{R S *}, p_{e}^{R S *}$, and $r^{R S *}$ is sensitive to the online-to-offline service price t of manufacturer. Specifically,

(1) Margin price $m^{R S *}$ in the offline channel decreases with the online-to-offline service price $t$ if $\beta_{1}<\beta \leq \beta_{m r s 3}$, but increases with the online-to-offline service price $t$ if $\beta>\beta_{m r s 3}$.

(2) Wholesale price $w^{R S *}$ in the offline channel decreases with the online-to-offline service price $t$.

(3) Retail price $p_{r}^{R S *}$ in the offline channel decreases with the online-to-offline service price $t$ if $\beta_{1}<\beta \leq \beta_{\text {prrs } 3}$, but increases with the online-to-offline service price $t$ if $\beta>\beta_{\text {prrs } 3}$.

(4) Retail price $p_{e}^{R S *}$ in the online channel decreases with the online-to-offline service price $t$ if $\beta_{1}<\beta \leq \beta_{\text {pers } 3}$, but increases with the online-to-offline service price $t$ if $\beta>\beta_{\text {pers } 3}$.

(5) Corporate environmental responsibility level $r^{R S *}$ decreases with the online-to-offline service price $t$. where $\beta_{m r s 3}=\left[k_{e} k_{r}\left(b_{1}^{2}+b_{2}^{2}\right)+b_{1} b_{2}\left(k_{e}^{2}+k_{r}^{2}\right)\right] /\left[2 b_{2}\left(b_{1}^{2}-b_{2}^{2}\right)\right], \beta_{\text {prrs } 3}=$ $\left[k_{e} k_{r}\left(b_{1}^{2}+b_{2}^{2}\right)+b_{1} b_{2}\left(k_{e}^{2}+k_{r}^{2}\right)\right] /\left[b_{2}\left(b_{1}^{2}-b_{2}^{2}\right)\right], \beta_{\text {pers } 3}=\left(b_{1} k_{e}+b_{2} k_{r}\right)^{2} /\left[b_{1}\left(b_{1}^{2}-b_{2}^{2}\right)\right]$.

The proof can be seen in Appendix A.

According to Propositions 3-5, we use Table 4 to show and compare the sensitivities of optimal policy to model parameters in Scenario RS. 
Table 4. The sensitivities of optimal policy to model parameters in Scenario RS.

\begin{tabular}{cccc}
\hline & $\alpha$ & $l$ & $t$ \\
\hline$m^{R S *}$ & $\downarrow \uparrow$ & $\uparrow \downarrow$ & $\downarrow \uparrow$ \\
$w^{R S *}$ & $\downarrow \uparrow$ & $\downarrow \uparrow$ & $\downarrow$ \\
$p_{r}^{R S *}$ & $\downarrow \uparrow$ & $\downarrow \uparrow \downarrow$ & $\downarrow \uparrow$ \\
$p_{e}^{R S *}$ & $\downarrow$ & $\downarrow \uparrow$ & $\downarrow \uparrow$ \\
$r^{R S *}$ & $\downarrow$ & $\downarrow \uparrow$ & $\downarrow$ \\
\hline
\end{tabular}

Notes: $\uparrow:$ increase; $\downarrow$ : decrease.

For impact trends of degree $\alpha$ in Table 4 , the reason is that, increasing $\alpha$ will reduce the demand in the online channel. To keep benefit, the manufacturer will decrease price $p_{e}^{R S *}$ to improve demand. To make up the loss, the manufacturer will decrease level $r^{R S *}$. Besides, increasing $\alpha$ will increase the demand in the offline channel and further increase the profit of retailer. For lower $\beta$, both online and offline channels can contribute to the profit of manufacturer, so the manufacturer and retailer will seek for the profit equilibrium by decreasing prices $w^{R S *}$ and $m^{R S *}$, and then price $p_{r}^{R S *}$ decreases accordingly. However, for higher $\beta$, the manufacturer will pay more attentions to the offline channel and seek for more profits from offline channel, so the manufacturer and retailer will try to realize profit equilibrium in the offline channel by increasing prices $w^{R S *}$ and $m^{R S *}$, and then price $p_{r}^{R S *}$ increases accordingly.

For impact trends of cost $l$ in Table 4 , the reason is that, for lower $\beta$, increasing $l$ will decrease the profit of retailer, and the retailer will increase price $m^{R S *}$ to share more profits in the offline channel. The manufacturer will decrease $w^{R S *}$ to transfer the profit to retailer, and will decrease price $p_{e}^{R S *}$ to improve demand in the online channel to realize profit equilibrium in both channels. Additionally, the manufacturer will decrease level $r^{R S *}$ to reduce the investment cost for corporate environmental responsibility. However, for higher $\beta$, the manufacturer suffers high investment cost for corporate environmental responsibility. The increasing $l$ will decrease the profit of retailer, but the retailer will decrease price $m^{R S *}$ to transfer the profit to the manufacturer, and the manufacturer will increase price $w^{R S *}$ to share more profit in the offline channel. Besides, the increasing $l$ will increase online-to-offline service cost, so the manufacturer will increase price $p_{e}^{R S *}$ to reduce demand in the online channel, and will further transfer profit from online channel to the offline channel. In addition, to retain the profits of manufacturer and retailer, the manufacturer will increase level $r^{R S *}$ to improve demands in two channels.

It is necessary to note that, price $p_{r}^{R S *}$ consists of prices $w^{R S *}$ and $m^{R S *}$, and price $p_{r}^{R S *}$ may decrease or increase. It is because that, for lower $\beta$, impact of cost $l$ on price $p_{r}^{R S *}$ mainly follows to the one on price $w^{R S *}$, so price $p_{r}^{R S *}$ will decrease accordingly. For higher $\beta$, impact of $\operatorname{cost} l$ on price $p_{r}^{R S *}$ mainly follows to the one on price $m^{R S *}$, so price $p_{r}^{R S *}$ will also decrease accordingly. However, for median $\beta$, the impact of $\operatorname{cost} l$ on price $p_{r}^{R S *}$ will be related to comprehensive impact on prices $w^{R S *}$ and $m^{R S *}$, price $p_{r}^{R S *}$ will increase.

For impact trends of service price $t$ in Table 4 , the reason is that, increasing $t$ will increase the profit of retailer but decrease the profit of manufacturer in online channel, then the manufacturer will decrease level $r^{R S *}$ to reduce the investment cost to retain the profit, and will decrease price $w^{R S *}$ to improve demand in the offline channel. Besides, for lower $\beta$, the retailer will decrease price $m^{R S *}$ to transfer profit to the manufacturer, and will accordingly decrease price $p_{r}^{R S *}$ to improve demand in the offline channel. The manufacturer will decrease price $p_{e}^{R S *}$ to improve demand in the online channel for benefit. However, for higher $\beta$, the manufacturer suffers from high investment cost for corporate environmental responsibility, so the profit equilibrium in both channels cannot be realized, thus the retailer will increase price $m^{R S *}$ to seek for the profit in the offline channel, the manufacturer will increase price $p_{e}^{R S *}$ to retain the profit. In addition, the impact of service price $t$ on price $p_{r}^{R S *}$ mainly follows the one on price $m^{R S *}$, so price $p_{r}^{R S *}$ will increase. 


\subsection{Scenario MS}

In scenario MS, the manufacturer is the leader in an online-to-offline supply chain. According to Stackelberg game and Equations (3) and (4), we can construct the joint pricing and corporate environmental responsibility-level decision model for Scenario MS, i.e., Model C.

$$
\text { Model C: } \begin{aligned}
& \max _{p_{e}, r, w} \pi_{M}\left(p_{e}, r, w \mid m\right)=(w-c) D_{r}+\left(p_{e}-c-t\right) D_{e}-\beta r^{2} / 2 \\
& \text { s.t. }\left\{\begin{array}{l}
m^{*} \in \operatorname{argmax} \pi_{R}\left(m \mid p_{e}, r, w\right)=\left(p_{r}-w\right) D_{r}+(t-l) D_{e} \\
p_{r}=m+w
\end{array}\right.
\end{aligned}
$$

By solving Model C, we can obtain following theoretical results.

Theorem 3. In Scenario MS, there is uniquely optimal joint decision policy of margin price $m^{M S *}$, wholesale price $w^{M S *}$, online retail price $p_{e}^{M S *}$, and corporate environmental responsibility level $r^{M S *}$, i.e.,

$$
\begin{aligned}
& m^{M S *}=\frac{k_{r}\left\{\begin{array}{l}
\left(b_{1}^{2}-b_{2}^{2}\right)\left\{b_{2}(c-l+2 t)+b_{1}\left[2 k_{e}(c+t)+c k_{r}\right]\right\} \\
-a \alpha k_{r}\left(b_{1}-b_{2}\right)^{2}-2 a b_{1}\left\{k_{e}\left[(1-\alpha) b_{1}+\alpha b_{2}\right]+b_{2} k_{r}\right\}
\end{array}\right\}}{4 b_{1}\left[\left(b_{1}^{2}+b_{2}^{2}\right) k_{r}^{2}-4 \beta b_{1}\left(b_{1}^{2}-b_{2}^{2}\right)+2 b_{1}{ }^{2} k_{e}^{2}+4 b_{1} b_{2} k_{r} k_{e}\right]}+\frac{b_{2}(c+4 t-3 l)+\left(a \alpha-c b_{1}\right)}{4 b_{1}} \\
& w_{R}^{M S *}=\frac{\left\{\begin{array}{l}
\left(4 \beta b_{1}{ }^{3} b_{2}-b_{2}{ }^{3} k_{r}{ }^{2}-4 \beta b_{1} b_{2}{ }^{3}\right)(t-l)-\left(4 \beta b_{1}{ }^{2} b_{2}+b_{1} b_{2} k_{r}^{2}+2 b_{1}{ }^{2} k_{r} k_{e}\right)(1-\alpha) a \\
+\left(2 b_{1}{ }^{2} k_{e}{ }^{2}-4 \beta b_{1}{ }^{3} c+b_{1} b_{2} k_{r} k_{e}\right) \alpha a+\left(b_{1}{ }^{2} b_{2} k_{r}{ }^{2}+2 b_{1}{ }^{3} k_{r} k\right)(t+c)+2 b_{1} b_{2} k_{e}{ }^{2}(c+l) \\
+b_{1} b_{2}{ }^{2} k_{r} k_{e}(c+3 l-2 t)+\left(2 b_{1}{ }^{3} k_{r}^{2}+2 b_{1}{ }^{3} k_{e}{ }^{2}-4 \beta b_{1}{ }^{4}+4 \beta b_{1}{ }^{2} b_{2}{ }^{2}+5 b_{1}{ }^{2} b_{2} k_{r} k_{e}+b_{1} b_{2}{ }^{2} k_{r}{ }^{2}\right) c
\end{array}\right\}}{2\left[\left(b_{1}^{2}+b_{2}{ }^{2}\right) k_{r}{ }^{2}-4 \beta b_{1}\left(b_{1}{ }^{2}-b_{2}{ }^{2}\right)+2 b_{1}{ }^{2} k_{e}{ }^{2}+4 b_{1} b_{2} k_{r} k_{e}\right]} \\
& p_{e}^{M S *}=\frac{\left\{\begin{array}{l}
\left(b_{1}^{2}+2 b_{2}^{2}+b_{1} b_{2}\right) c k_{r}^{2}+\left[\left(b_{1}^{2}+3 b_{2}^{2}\right)+2\left(2 b_{1} k_{e}+4 b_{2} k_{r}\right) b_{1} k_{e} k_{r}^{2}\right] t \\
+4 b_{1}^{2} c k_{e}^{2}-\left(b_{2}^{2} k_{r}^{2}-b_{1} b_{2} k_{r} k_{e}\right) l-4 \beta b_{1}^{2} a(1-\alpha)-4 \beta b_{1} b_{2} \alpha a-4 \beta b_{1}{ }^{3} c \\
-4 \beta b_{1}{ }^{3} t+b_{1} k_{r}^{2}(1-\alpha) a-k_{e} k_{r} b_{1} \alpha a+4 \beta b_{1} b_{2}^{2}(t+c)+\left(b_{1}^{2}+7 b_{1} b_{2}\right) c k_{r} k_{e}
\end{array}\right\}}{2\left[\left(b_{1}^{2}+b_{2}{ }^{2}\right) k_{r}{ }^{2}-4 \beta b_{1}\left(b_{1}{ }^{2}-b_{2}{ }^{2}\right)+2 b_{1}{ }^{2} k_{e}{ }^{2}+4 b_{1} b_{2} k_{r} k_{e}\right]} \\
& r^{M S *}=\frac{\left\{\begin{array}{l}
\left(b_{1}{ }^{2} b_{2} k_{r}-b_{2}{ }^{3} k_{r}\right)(c+2 t-l)-\left(2 b_{1}{ }^{2} k_{e}+2 b_{1} b_{2} k_{r}\right)(1-\alpha) a-\left[\left(b_{1}{ }^{2}+b_{2}{ }^{2}\right) k_{r}+2 b_{1} b_{2} k_{e}\right] \alpha a \\
+2 b_{1}^{3}\left[k_{e}(c+t)+k_{r} c\right]-2 b_{1} b_{2}{ }^{2}\left[k_{e}(c-t)+k_{r} c\right]
\end{array}\right\}}{\left(b_{1}{ }^{2}+b_{2}{ }^{2}\right) k_{r}{ }^{2}-4 \beta b_{1}\left(b_{1}{ }^{2}-b_{2}{ }^{2}\right)+2 b_{1}{ }^{2} k_{e}{ }^{2}+4 b_{1} b_{2} k_{r} k_{e}}
\end{aligned}
$$

The proof can be seen in Appendix A.

Furthermore, we can obtain optimal retail price $p_{r}^{M S *}$ in the offline channel according to Equations (13) and (14), i.e.,

$$
p_{r}^{M S *}=\frac{\left\{\begin{array}{l}
-b_{2}(c+2 t-l)\left[2 \beta\left(b_{1}^{2}-b_{2}^{2}\right)-b_{1}\left(k_{e}^{2}+2 k_{r}^{2}\right)-3 b_{2} k_{r} k\right]+3 a \alpha b_{1} k_{e}^{2} \\
-4 a \alpha \beta b_{1}^{2}-(c+t)\left[\left(b_{2}^{2}-3 b_{1}^{2}\right) k_{r} k_{e}-2 b_{1} b_{2} k_{e}^{2}\right]+2 a b_{2} k_{r}\left[\alpha k_{e}-(1-\alpha) k_{r}\right] \\
+3 b_{1} k_{e} k_{r}\left[c b_{2}-(1-\alpha) a\right]+c b_{1}^{2}\left(k_{e}^{2}+2 k_{r}^{2}\right)-2 \beta\left[2 a b_{1} b_{2}(1-\alpha)+\left(a \alpha+c b_{1}\right)\left(b_{1}^{2}-b_{2}^{2}\right)\right]
\end{array}\right\}}{2\left[\left(b_{1}^{2}+b_{2}^{2}\right) k_{r}^{2}-4 \beta b_{1}\left(b_{1}^{2}{ }^{2}-b_{2}^{2}{ }^{2}\right)+2 b_{1}{ }^{2} k_{e}{ }^{2}+4 b_{1} b_{2} k_{r} k_{e}\right]}
$$

Proposition 6. In Scenario MS, the optimal joint decision policy of $m^{M S *}, w^{M S *}, p_{r}^{M S *}, p_{e}^{M S *}$, and $r^{M S *}$ is sensitive to preference degree $\alpha$ of the consumer to the offline channel. Specifically,

(1) Margin price $m^{M S *}$ in the offline channel decreases with degree $\alpha$ if $\beta_{1}<\beta \leq \beta_{m m s 1}$, but increases with degree $\alpha$ if $\beta>\beta_{m m s 1}$.

(2) Wholesale price $w^{M S *}$ in the offline channel decreases with degree $\alpha$ if $\beta_{1}<\beta \leq \beta_{\text {wms } 1}$, but increases with degree $\alpha$ if $\beta>\beta_{\text {wms } 1}$.

(3) Retail price $p_{r}^{M S *}$ in the offline channel decreases with degree $\alpha$ if $\beta_{1}<\beta \leq \beta_{\text {prms } 1 \text {, but }}$ increases with degree $\alpha$ if $\beta>\beta_{\text {prms } 1}$.

(4) Retail price $p_{e}^{M S *}$ in the online channel decreases with degree $\alpha$.

(5) Corporate environmental responsibility level $r^{M S *}$ decreases with degree $\alpha$. where $\beta_{m m s 1}=$ $\left(b_{1} k_{e}+b_{2} k_{r}\right)\left(k_{r}+k_{e}\right) /\left[2\left(b_{1}^{2}-b_{2}^{2}\right)\right], \beta_{w m s 1}=\left(2 b_{1} k_{e}+b_{2} k_{r}\right)\left(k_{r}+k_{e}\right) /\left[4\left(b_{1}^{2}-b_{1} b_{2}\right)\right]$, $\beta_{\text {prms } 1}=\left(3 b_{1} k_{e}+2 b_{2} k_{r}\right)\left(k_{r}+k_{e}\right) /\left[2\left(3 b_{1}^{2}-2 b_{1} b_{2}-b_{2}^{2}\right)\right]$.

The proof can be seen in Appendix A. 
Proposition 7. In Scenario MS, the optimal joint decision policy of $m^{M S *}, w^{M S *}, p_{r}^{M S *}, p_{e}^{M S *}$, and $r^{M S *}$ is sensitive to online-to-offline service cost $l$ of retailer. Specifically,

(1) Margin price $m^{M S *}$ in the offline channel decreases with the online-to-offline service cost $l$.

(2) Wholesale price $w^{M S *}$ in the offline channel increases with the online-to-offline service cost $l$.

(3) Retail price $p_{r}^{M S *}$ in the offline channel increases with the online-to-offline service cost $l$ if $\beta_{1}<\beta \leq \beta_{\text {prms2 }}$, but decreases with the online-to-offline service cost l if $\beta>\beta_{m m s 2}$.

(4) Retail price $p_{e}^{M S *}$ in the online channel increases with the online-to-offline service cost $l$.

(5) Corporate environmental responsibility level $r^{M S *}$ increases with the online-to-offline service cost l. where $\beta_{\text {prms } 2}=\left[b_{1}\left(2 k_{r}^{2}+k_{e}^{2}\right)+3 b_{2} k_{r} k_{e}\right] /\left[2\left(b_{1}^{2}-b_{2}^{2}\right)\right]$.

The proof can be seen in Appendix A.

Proposition 8. In Scenario MS, the optimal joint decision policy of $m^{M S *}, w^{M S *}, p_{r}^{M S *}, p_{e}^{M S *}$, and $r^{M S *}$ is sensitive to online-to-offline service price tof manufacturer. Specifically,

(1) Margin price $m^{M S *}$ in the offline channel decreases with the online-to-offline service price $t$ if $\beta_{1}<\beta \leq \beta_{m m s 3}$, but increases with the online-to-offline service price $t$ if $\beta>\beta_{m m s 3}$.

(2) Wholesale price $w^{M S *}$ in the offline channel decreases with the online-to-offline service price $t$.

(3) Retail price $p_{r}^{M S *}$ in the offline channel decreases with the online-to-offline service price $t$ if $\beta_{1}<\beta \leq \beta_{\text {prms3 }}$, but increases with the online-to-offline service price $t$ if $\beta>\beta_{\text {prms3 }}$.

(4) Retail price $p_{e}^{M S *}$ in the online channel decreases with the online-to-offline service price tif $\beta_{1}<\beta \leq \beta_{\text {pems3 }}$, but increases with the online-to-offline service price $t$ if $\beta>\beta_{\text {pems3 }}$.

(5) Corporate environmental responsibility level $r^{M S *}$ decreases with the online-to-offline service price t.

$$
\begin{aligned}
& \text { where } \beta_{m m s 3}=\left[\left(b_{1}^{2}+7 b_{2}^{2}\right) b_{1} k_{e} k_{r}+b_{1}{ }^{2} b_{2}\left(3 k_{r}^{2}+4 k_{e}{ }^{2}\right)+b_{2}{ }^{3} k_{r}{ }^{2}\right] /\left[8 b_{1} b_{2}\left(b_{1}{ }^{2}-b_{2}{ }^{2}\right)\right], \\
& \beta_{\text {prms } 3}=\left[4 b_{1} b_{2}\left(k_{r}^{2}+k_{e}{ }^{2}\right)+k_{r} k_{e}\left(3 b_{1}^{2}+5 b_{2}^{2}\right)\right] /\left[4 b_{2}\left(b_{1}{ }^{2}-b_{2}^{2}\right)\right], \\
& \beta_{\text {pems } 3}=\left[4\left(b_{1} k_{e}+b_{2} k_{r}\right)^{2}+\left(b_{1}{ }^{2}-b_{2}{ }^{2}\right) k_{r}^{2}\right] /\left[4 b_{1}\left(b_{1}{ }^{2}-b_{2}{ }^{2}\right)\right] .
\end{aligned}
$$

The proof can be seen in Appendix A.

According to Propositions 6-8, we use Table 5 to show and compare the sensitivities of optimal policy to model parameters in Scenario MS.

Table 5. The sensitivities of optimal policy to model parameters in Scenario MS.

\begin{tabular}{cccc}
\hline & $\alpha$ & $l$ & $t$ \\
\hline$m^{M S *}$ & $\downarrow \uparrow$ & $\downarrow$ & $\downarrow \uparrow$ \\
$w^{M S *}$ & $\downarrow \uparrow$ & $\uparrow$ & $\downarrow$ \\
$p_{r}^{M S *}$ & $\downarrow \uparrow$ & $\uparrow \downarrow$ & $\downarrow \uparrow$ \\
$p_{e}^{M S *}$ & $\downarrow$ & $\uparrow$ & $\downarrow \uparrow$ \\
$r^{M S *}$ & $\downarrow$ & $\uparrow$ & $\downarrow$ \\
\hline
\end{tabular}

Notes: $\uparrow:$ increase; $\downarrow$ : decrease.

For impact trends of cost $l$ in Table 5, the reason is that, increasing $l$ will decrease the profit of retailer in the online channel, so the retailer will decrease price $m^{M S *}$ to try to reduce the demand in the online channel. However, the manufacturer will seize the chance to increase price $w^{M S *}$ to seek for more profits in the offline channel, and will increase level $r^{M S *}$ to improve the demand in both channels, and will further increase price $p_{e}^{M S *}$ for benefit. Besides, price $p_{r}^{M S *}$ is consisted of prices $w^{M S *}$ and $m^{M S *}$, and price $p_{r}^{M S *}$ may decrease or increase. It is because that, for lower $\beta$, impact of cost $l$ on price $p_{r}^{M S *}$ mainly follows to the one on price $w^{R S *}$, so price $p_{r}^{M S *}$ will increase accordingly. However, for higher $\beta$, impact of cost $l$ on price $p_{r}^{M S *}$ mainly follows to the one on price $m^{R S *}$, so price $p_{r}^{M S *}$ will decrease accordingly.

For impact trends of degree $\alpha$ and service price $t$ in Table 5, they are similar to the ones in Table 4, so we do not repeat them here. 
Through the comparison analysis of theoretical results in Tables 4 and 5, we find that, under different supply chain power structures, there are no significant differences with respect to impacts of parameters $\alpha$ and $t$, but there are significant differences with respect the impacts of cost $l$, i.e., the impact of cost $l$ in manufacturer Stackelberg game will be generally not related to the investment cost sensitivity $\beta$. It indicates that supply chain power structure cannot affect impact trends of degree $\alpha$ and service price $t$ on the optimal joint decision problem, but can affect impact trends of cost $l$. Therefore, the supply chain members need to pour attentions to the parameter environment and power structure in their practical decisions.

\section{Coordination Analysis}

In this section, we conduct the coordination analysis by designing a revenue-sharing contract for Scenarios RS and MS, and analyze the impacts of the investment cost sensitivity $\beta$ and revenue sharing rates $\lambda$ and $\gamma$ on profit differences of retailer and manufacturer between centralized and decentralized decisions. Following extant literature [82], we consider that supply chain coordinates if the optimal joint decision policy in Scenario RS or MS is equal to the one in centralized decision. To illustrate clearly the coordination analysis in two scenarios, we provide the frameworks for each scenario:

For Scenarios RS, the framework contains Model D, Theorem 4, Proposition 9, and Figures 2 and 3 for testifying the results in Theorem 4 and Proposition 9.

For Scenario MS, the framework contains Model F, Theorem 5, Proposition 10, and Figures 4 and 5 for testifying the results in Theorem 5 and Proposition 10.

\subsection{Scenario $R S$}

In Scenario RS, we use a revenue-sharing contract to realize supply chain coordination. In the contract, the manufacturer will incentive the retailer to accept the contract by feasible wholesale price $w$, and the retailer will share rate $\lambda$ of revenue to the manufacturer. Then, we can build profit functions of retailer and manufacture in revenue-sharing contract in an online-to-offline supply chain. According to Stackelberg game, we can construct the joint pricing and corporate environmental responsibility-level decision model below.

$$
\begin{gathered}
\max _{m^{R C *}} \pi_{R}^{R C}=\left[(1-\lambda) p_{r}-w\right] D_{r}+(t-l) D_{e} \\
\text { Model D: } \quad \begin{array}{l}
w^{R C *} \in \operatorname{argmax} \pi_{M}^{R C}=\left(\lambda p_{r}+w-c\right) D_{r}+\left(p_{e}-c-t\right) D_{e}-\frac{\beta r^{2}}{2} \\
r^{R C *}=r^{C D *}, p_{e}^{R C *}=p_{e}^{C D *}, p_{r}^{R C *}=p_{r}^{C D *}, p_{r}^{R C *}=w^{R C *}+m^{R C *} \\
\pi_{M}^{R C *} \geq \pi_{M}^{R S *}, \pi_{R}^{R C *} \geq \pi_{R}^{R S *} \\
0 \leq \lambda \leq 1
\end{array}
\end{gathered}
$$

By coordination analysis, we can obtain the following theoretical results.

Theorem 4. In Scenario $R S$, the revenue-sharing contract can realize supply chain coordination if $p_{e}^{R C *}=p_{e}^{C D *}, p_{r}^{R C *}=p_{r}^{C D *}$, and $r^{R C *}=r^{C D *}$, and further coordinated wholesale price $w^{R C *}$ can be determined, i.e.,

$$
\begin{aligned}
\left\{a\left[\alpha b_{1}+(1-\alpha) \lambda b_{2}\right]-c\left(b_{1}^{2}-\lambda b_{2}^{2}\right)\right\} k_{r}^{2}-(c+l)(1-\lambda) b_{1} b_{2} k_{e}^{2}+2 a \beta(1-\lambda)\left[(1-\alpha) b_{1}+\alpha b_{2}\right] \\
+k_{e} k_{r}\left\{\alpha\left[(1-\alpha) b_{1}+(2-\lambda) \alpha b_{2}\right]-(c+c l)\left(b_{1}^{2}-\lambda b_{2}^{2}\right)-(1-\lambda) c b_{1} b_{2}\right\} \\
w^{R C *}=\frac{+a \alpha+(1-2 \lambda) c b_{1}+b_{2}[(2+\lambda) c l-2 t+c \lambda]\left[2 \beta\left(b_{1}^{2}-b_{2}^{2}\right)-b_{1}\left(k_{e}^{2}+k_{r}^{2}\right)-2 b_{2} k_{e} k_{r}\right]}{2 b_{1}\left[2 \beta\left(b_{1}^{2}-b_{2}^{2}\right)-b_{1}\left(k_{e}^{2}+k_{r}^{2}\right)-2 b_{2} k_{e} k_{r}\right]}
\end{aligned}
$$

The proof can be seen in Appendix A. 
Proposition 9. In Scenario RS, the manufacturer and retailer are willing to use the revenue-sharing contract to coordinate supply chain if and only if $\lambda_{1}<\lambda<\lambda_{2}$, where

$$
\begin{aligned}
\lambda_{1} & =\left[(t+c)\left(D_{e}^{R C *}-D_{e}^{R S}\right)-p_{e}^{R C *} D_{e}^{R C *}+p_{e}^{R S *} D_{e}^{R S *}+\left(w^{R S *}-c\right) D_{r}^{R S *}\right] /\left(p_{r}^{R C *} D_{r}^{R C *}\right)-\left(w^{R C *}-c\right) / p_{r}^{R C *} \\
& +\beta\left[\left(r^{R C *}\right)^{2}-\left(r^{R S *}\right)^{2}\right] /\left(2 p_{r}^{R C *} D_{r}^{R C *}\right), \\
\lambda_{2} & =\left[\left(t-l+m^{R C *}\right) D_{r}^{R C *}-\left(t-l+m^{R S *}\right) D_{r}^{R S *}\right] /\left(p_{r}^{R C *} D_{r}^{R C *}\right) .
\end{aligned}
$$

It is easy to see from the comparison with respect to profits of each supply chain firm between Scenario RS in revenue-sharing contract and Scenario CD, so we will not provide the proof in detail.

To illustrate and testify theoretical result in Proposition 9 in Scenario RS, we conduct the following numerical study to show the impacts of revenue-sharing rate $\lambda$ and investment cost sensitivity $\beta$ for corporate environmental responsibility. Given the assumptions and coordination conditions, i.e., $b_{1}>b_{2}, k_{e}>k_{r}, c l<t<p_{e}-c, \beta>\beta_{1}$, and $\beta>\beta_{2}$, we determine without loss of generality parameters' values, i.e., $a=100, b_{1}=5, b_{2}=3, c=5$, $k_{e}=3, k_{r}=1, l=5, t=10$, and $\alpha=0.3$. In specific analysis, we analyze the impacts of revenue-sharing rate $\lambda$ for lower investment cost sensitivity $\beta(\beta=5)$ as shown in Figure 2 and for higher investment cost sensitivity $\beta(\beta=25)$ as shown in Figure 3 .

We find from Figures 2 and 3 that, with the increase of rate $\lambda$ in Scenario RS, the retailer's profit difference between coordination and non-coordination changes from positive to negative, but the manufacturer's profit difference between coordination and noncoordination is always positive and increases. It indicates that the manufacturer can always benefit from the coordination realized by revenue-sharing contract, but the retailer can benefit from the coordination only for lower rate $\lambda$, and will deny revenue-sharing contract if rate $\lambda$ is higher. Obviously, for higher $\lambda$, the revenue-sharing contract cannot realize supply chain coordination.

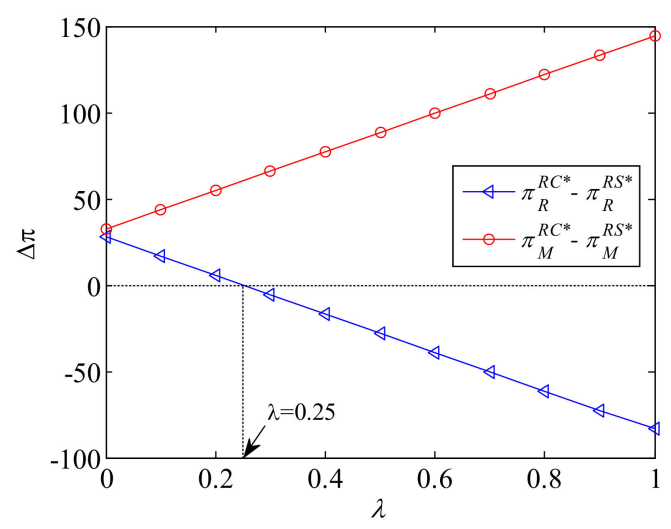

Figure 2. The impact of revenue sharing rate $\lambda$ on profit differences between coordination and non-coordination for Scenario RS when $\beta=5$.

Figure 2 shows that, for lower $\beta$, the manufacturer and retailer are willing to use revenue-sharing contract to realize supply chain coordination when $\lambda \in[0,0.25]$. In addition, at the point $\lambda=0.25$, the revenue-sharing contract can still realize supply chain coordination, and the retailer's profit difference is zero, but the manufacturer's profit difference takes the maximum in coordination. From Figure 3, we find that the manufacturer and retailer are willing to use revenue-sharing contract to realize supply chain coordination when $\lambda \in[0,0.18]$. 


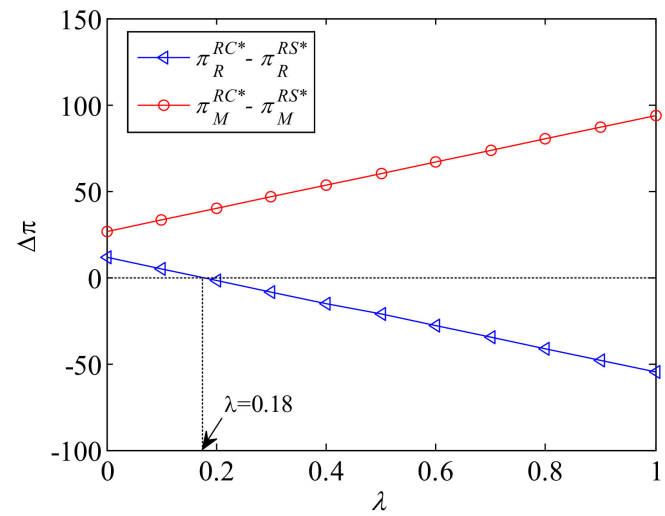

Figure 3. The impact of revenue sharing rate $\lambda$ on profit differences between coordination and non-coordination for Scenario RS when $\beta=25$.

By comparison analysis in Figures 2 and 3, we find the investment cost sensitivity cannot affect the coordination capability of revenue-sharing contract, but can affect the coordination range with respect to rate $\lambda$. In addition, the higher the investment cost sensitivity $\beta$ is, the greater the changing extent of profit differences between coordination and non-coordination with respect to rate $\lambda$ is. It indicates that investment cost sensitivity $\beta$ can affect the impact effectiveness of rate $\lambda$ on profit differences between coordination and non-coordination.

\subsection{Scenario MS}

In Scenario MS, the coordination analysis is similar to the one in Scenario RS. Specifically, we build the profit functions of retailer and manufacture in revenue-sharing contract in an online-to-offline supply chain. According to Stackelberg game, we construct the joint pricing and corporate environmental responsibility-level decision model below.

Model E: $\quad$ s.t. $\left\{\begin{array}{l}m^{M C *} \in \operatorname{argmax} \pi_{R}^{M C}=\left[(1-\gamma) p_{r}-w\right] D_{r}+(t-l) D_{e} \\ r^{M C *}=r C D *, p_{e}^{M C *}=p_{e}^{C D *}, p_{r}^{M C *}=p_{r}^{C D *}, p_{r}^{M C *}=w^{M C *}+m^{M C *} \\ \pi_{M}^{M C *} \geq \pi_{M}^{M S *}, \pi_{R}^{M C *} \geq \pi_{R}^{M S *} \\ 0 \leq \gamma \leq 1\end{array}\right.$

By coordination analysis, we can obtain the following theoretical results.

Theorem 5. In Scenario MS, the revenue-sharing contract can realize supply chain coordination if $p_{e}^{M C *}=p_{e}^{C D *}, p_{r}^{M C *}=p_{r}^{C D *}$, and $r^{M C *}=r^{C D *}$, and further coordinated wholesale price $w^{M C *}$ can be determined, i.e.,

$$
\begin{aligned}
& b_{2}(1-\gamma)\left\{b_{1} k_{e}^{2}(c+l)-2 a \alpha \beta b_{2}+\left[c b_{2}+a(1-\alpha)\right] k_{r}^{2}\right\} \\
&-\left\{2 a \beta b_{1}(1-\alpha)+k_{r} k_{e}\left[a \alpha-c b_{1}-b_{2}(c+l)\right]\right\} b_{2}(1-\gamma) \\
& w^{M C *}=\frac{+\left\{c(1-\gamma)\left(2 b_{1}-b_{2}\right)+b_{2}[(1+\gamma) l-2 t]\right\}\left[b_{1}\left(k_{r}^{2}+k_{e}^{2}\right)+2 b_{2} k_{r} k_{e}-2 \beta\left(b_{1}{ }^{2}-b_{2}{ }^{2}\right)\right]}{2 b_{1}\left[b_{1}\left(k_{r}^{2}+k_{e}^{2}\right)+2 b_{2} k_{r} k_{e}-2 \beta\left(b_{1}{ }^{2}-b_{2}{ }^{2}\right)\right]}
\end{aligned}
$$

The proof can be seen in Appendix A.

Proposition 10. In Scenario MS, the manufacturer and retailer are willing to use the revenuesharing contract to coordinate supply chain if and only if $\gamma_{1}<\gamma<\gamma_{2}$, where

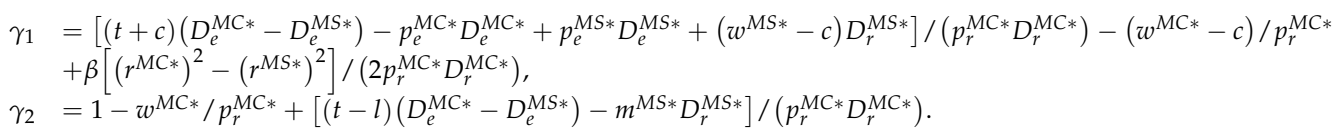


It is easy to see from the profit comparison between Scenario MS in revenue-sharing contract and Scenario CD, so we will not provide the proof in detail.

Similar to Figures 2 and 3, we conduct following numerical study to illustrate and testify theoretical result in Proposition 10 in Scenario MS, and can obtain from Figures 4 and 5 some similar analysis results as shown in Figures 2 and 3. It is necessary to note that, in Figures 4 and 5, the manufacturer and retailer are willing to use revenue-sharing contract to realize supply chain coordination when $\gamma \in[0.88,1]$ for lower $\beta$ and when $\gamma \in[0.84,1]$ for higher $\beta$. It indicates that the supply chain coordination range with respect to rate $\gamma$ for higher $\beta$ is greater than the one for lower $\beta$.

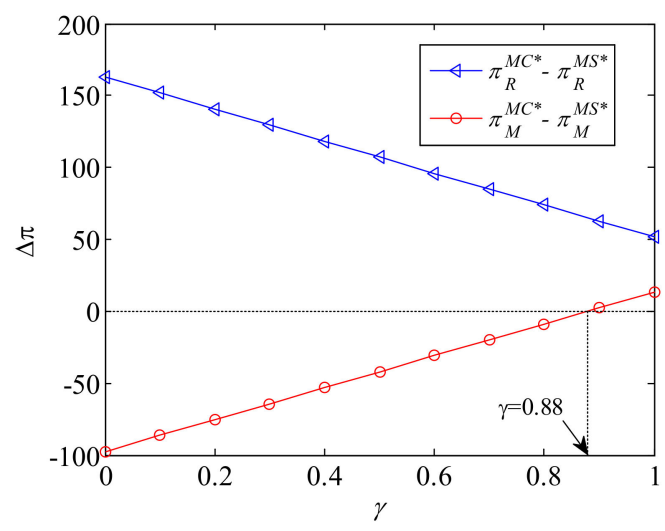

Figure 4. The impact of revenue sharing rate $\gamma$ on profit differences between coordination and non-coordination for Scenario MS when $\beta=5$.

By comparison of Figures 2-5 in Scenarios RS and MS, we find three significant differences caused by supply chain power structure:

(1) The retailer needs to share more revenues to the manufacturer for supply chain coordination in manufacturer Stackelberg game than the one in retailer Stackelberg game. This is because in retailer Stackelberg game, the retailer has higher bargaining power. She will decide a lower margin price to transfer some profits to the manufacturer and then can require a lower revenue-sharing rate. However, in the manufacturer Stackelberg game, the manufacturer has higher bargaining power. He can require a higher revenue-sharing rate to realize supply chain coordination by a lower wholesale price.

(2) For different supply chain power structures, profit differences of manufacturer and retailer between coordination and non-coordination differ. In the retailer Stackelberg game, the manufacturer's profit difference is positive and increases with revenue-sharing rate, but the retailer's profit difference changes from positive to negative. In the manufacturer Stackelberg game, the manufacturer's profit difference changes from negative to positive, but the retailer's profit difference is positive and decreases with revenue-sharing rate. Obviously, the profit differences with respect to supply chain leader change from positive to negative or from negative to positive, but the profit differences with respect to supply chain follower are always positive. The reason is that the supply chain leader has the power to make a more profitable decision so the profit difference between coordination and non-coordination is relatively small, and thus changes from positive to negative or from negative to positive. It indicates that the supply chain leader conditionally accepts the coordination contract, but the supply chain follower always accepts. 


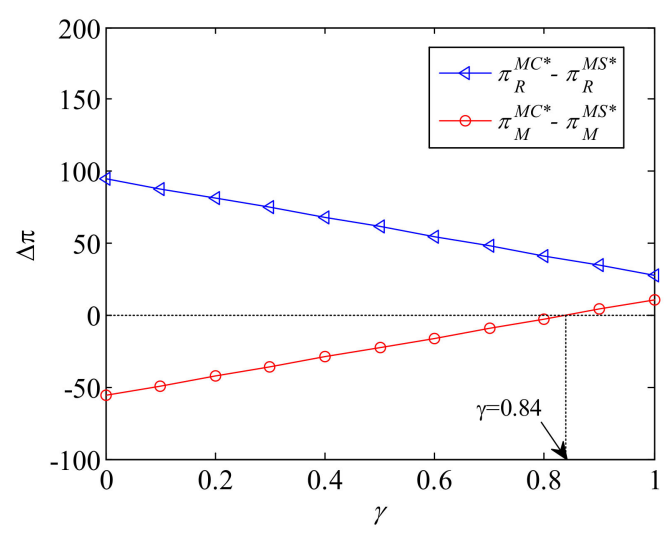

Figure 5. The impact of revenue sharing rate $\gamma$ on profit differences between coordination and non-coordination for Scenario MS when $\beta=25$.

(3) The supply chain power structure can affect the impact of the investment cost sensitivity on coordination range with respect to the revenue-sharing rate. In retailer Stackelberg game, coordination range with respect to revenue-sharing rate is $[0,0.25]$ for lower $\beta$ but $[0,0.18]$ for higher $\beta$. In the manufacturer's Stackelberg game, the coordination range with respect to revenue-sharing rate is $[0.88,1]$ for lower $\beta$ but $[0.84,1]$ for higher $\beta$. It indicates that the coordination range with respect to revenue-sharing rate extends with the investment cost sensitivity $\beta$ in the retailer Stackelberg game, but narrows with $\beta$ in the manufacturer's Stackelberg game.

From the above analysis, we find the supply chain power structure can affect onlineto-offline supply chain coordination conditions considering corporate environmental responsibility and lateral inventory transshipment, and thus the manufacturer and retailer need to pay attention to power structure characteristics in their practical decision.

It is necessary to note that these results derive from numerical studies, but they can still illustrate and testify theoretical results in Theorems 4 and 5 and Propositions 9 and 10.

\section{Management Insights}

To guide supply chain firms in their practical decisions, we provide managerial insights according to obtained theoretical results below.

(1) The optimal joint pricing and corporate environmental responsibility-level decision policies for three scenarios are uniquely determined, and can be affected by significant parameters, but the effects are not monotonic. Thus, the supply chain firms need to determine optimal policy with respect to the practical parameter environment. If the parameter environment changes, they need to make timely adjustments according to the theoretical results in this study. Specifically, in Scenario CD, for higher preference degree of the consumer to the offline channel, the manufacturer needs to set a lower price in the online channel and corporate environmental responsibility level; for higher online-to-offline service cost, the retailer needs to make lower price in the offline channel, and the manufacturer needs to make lower corporate environmental responsibility level. In Scenario RS, for higher preference degree of the consumer to the offline channel or higher online-to-offline service price, the manufacturer needs to make lower corporate environmental responsibility level. In Scenario MS, for higher online-to-offline service cost, the retailer needs to make a lower margin price, and the manufacturer needs to make a higher price in the online channel and corporate environmental responsibility level.

(2) The revenue-sharing contract can realize supply chain coordination in Scenarios RS and MS, but the coordination conditions for two the scenarios are different. To realize a win-win equilibrium, the supply chain leader needs to comprehensively consider the profit expectations of both supply chain firms. In Scenario RS, the retailer is the leader of supply chain, and has more power to take priority to make decisions. In this scenario, the retailer will trend to share lower revenue with the manufacturer. In Scenario MS, the manufacturer 
is the leader of supply chain, and has more power to take priority to make decision. In this scenario, the manufacturer will trend to seek higher revenue from the retailer. In both scenarios, the supply chain follower can deny a revenue contract if the supply chain leader badly hurts the profits of the follower.

(3) The supply chain power structure, revenue-sharing rate, and investment cost sensitivity can directly affect the coordination conditions for Scenarios RS and MS, and the supply chain power structure can affect the impact of investment cost sensitivity on coordination conditions with respect to revenue-sharing rate. Specifically, in Scenario RS, the higher the investment cost sensitivity is, the narrower the coordination condition range with respect to revenue-sharing rate is. The retailer will hold more profits of the supply chain. In Scenario MS, the higher the investment cost sensitivity is, the wider the coordination condition range with respect to revenue-sharing rate is. The manufacturer will hold more profits from the supply chain.

\section{Conclusions}

In this paper, we investigated the pricing and coordination problems in an onlineto-offline supply chain considering corporate environmental responsibility and lateral inventory transshipment. First, we analyze the structure and interaction process of supply chain, and construct joint pricing and corporate environmental responsibility-level decision models for three decision scenarios: CD, RS, and MS. By solving constructed models, we determine optimal joint decision policies for three scenarios, and provide the impact analysis of significant model parameters. Furthermore, we conduct the coordination analysis of the supply chain using a revenue-sharing contract in retailer and manufacturer Stackelberg games, and provide theoretical and numerical studies to show the impacts of significant factors, and further show the effect of supply chain power structure on the coordination by comparison.

We find that the optimal joint pricing and corporate environmental responsibility-level decision policy is uniquely determined for each scenario, and the policies for Scenarios RS and MS can be affected by the preference degree of the consumer to the offline channel, investment cost sensitivity to corporate environmental responsibility, and online-to-offline service price of manufacturer, but the policy for Scenario CD can be only affected by the preference degree and investment cost sensitivity. We also find the revenue-sharing contract can be used to realize the coordination of supply chain considering corporate environmental responsibility and lateral inventory transshipment, and that the coordination conditions are directly related to revenue-sharing rate and investment cost sensitivity to corporate environmental responsibility, and can also be affected by supply chain power structure difference.

Our study still has some limitations; these limitations will lead to further study. (1) We do not consider the impacts of stochastic demand and yield uncertainty, but the stochastic demand and yield uncertainty are important factors in some practical decisions. For further study, we will investigate the impacts of stochastic demand and yield uncertainty on optimal policy of supply chain considering corporate environmental responsibility and lateral inventory transshipment. (2) We do not consider the market competition, but product competition is also an important factor in reality. For further study, we will also try to conduct the study in competitive environment.

Author Contributions: Conceptualization, B.C. and T.Y.; methodology, B.C. and C.L.; software, J.Z.; validation, B.C. and T.Y.; formal analysis, B.C. and T.Y.; writing-original draft preparation, J.Z., C.L. and B.C.; writing-review and editing, B.C. and T.Y.; supervision, B.C. and T.Y.; project administration, B.C.; funding acquisition, B.C. All authors have read and agreed to the published version of the manuscript.

Funding: This work is partly supported by National Natural Science Foundation of China under Grant No. 72002054, National Social Science Foundation of China under Grant Nos. 18ZDA043 and 20BGL187, Science Foundation of the Ministry of Education of China under Grant No. 21YJC630043, GuangDong Basic and Applied Basic Research Foundation under Grant No. 2020A1515110618, 
Science and Technology Planning Project of Guangdong Province under Grant No. 2020A1414010084, University Research Project of Guangzhou Educational Bureau under Grant No. 202032853.

Institutional Review Board Statement: Not applicable.

Informed Consent Statement: Not applicable.

Data Availability Statement: Not applicable.

Conflicts of Interest: The authors declare no conflict of interest.

\section{Appendix A}

Proof of Theorem 1. According to Model A, we can determine Hessian matrix $H_{1}$ of $\pi_{S C}\left(p_{r}, p_{e}, r\right)$ with respect to $p_{r}, p_{e}$ and $r$.

$$
H_{1}=\left(\begin{array}{lll}
\frac{\partial^{2} \pi_{S C}}{\partial p_{r}^{2}} & \frac{\partial^{2} \pi_{S C}}{\partial p_{r} \partial p_{e}} & \frac{\partial^{2} \pi_{S C}}{\partial p_{S} \partial r} \\
\frac{\partial^{2} \pi_{S C}}{\partial p_{e} \partial p_{r}} & \frac{\partial^{2} \pi_{S C}}{\partial p_{e}^{2}} & \frac{\partial^{2} \pi_{S C}}{\partial p_{2} \partial r} \\
\frac{\partial^{2} \pi_{S C}}{\partial r \partial p_{r}} & \frac{\partial^{2} \pi_{S C}}{\partial r \partial p_{e}} & \frac{\partial^{2} \pi_{S C}}{\partial r^{2}}
\end{array}\right)=\left(\begin{array}{ccc}
-2 b_{1} & 2 b_{2} & k_{r} \\
2 b_{2} & -2 b_{1} & k_{e} \\
k_{r} & k_{e} & -\beta
\end{array}\right)
$$

Obviously, matrix $H_{1}$ is negative definite if $\beta>\beta_{1}=\left[b_{1}\left(k_{e}^{2}+k_{r}^{2}\right)+2 b_{2} k_{e} k_{r}\right] /\left[2\left(b_{1}^{2}-b_{2}^{2}\right)\right]$, it implies that, $\pi_{S C}\left(p_{r}, p_{e}, r\right)$ is a joint concave function with respect to $p_{r}, p_{e}$, and $r$, and has uniquely optimal policy. On the basis, by $\partial \pi_{S C} / \partial p_{r}=0, \partial \pi_{S C} / \partial p_{e}=0$, and $\partial \pi_{S C} / \partial r=0$, then we can determine the optimal policy, i.e., $p_{r}^{C D *}, p_{e}^{C D *}$, and $r^{C D *}$.

Proof of Proposition 1. According to Equations (5)-(7), we can obtain first order derivatives of optimal joint decision policy with respect to parameter $\alpha$, i.e.,

$$
\begin{gathered}
\frac{\partial p_{r}^{C D *}}{\partial \alpha}=\frac{a\left[k_{e}\left(k_{r}+k_{e}\right)-2 \beta\left(b_{1}-b_{2}\right)\right]}{2\left[b_{1}\left(k_{e}^{2}+k_{r}^{2}\right)+2 b_{2} k_{e} k_{r}-2 \beta\left(b_{1}^{2}-b_{2}^{2}\right)\right]} \\
\frac{\partial p_{e}^{C D *}}{\partial \alpha}=-\frac{a\left[k_{r}\left(k_{r}+k_{e}\right)-2 \beta\left(b_{1}-b_{2}\right)\right]}{2\left[b_{1}\left(k_{e}^{2}+k_{r}^{2}\right)+2 b_{2} k_{e} k_{r}-2 \beta\left(b_{1}^{2}-b_{2}^{2}\right)\right]} \\
\frac{\partial r C D *}{\partial \alpha}=\frac{a\left(b_{1}-b_{2}\right)\left(k_{e}-k_{r}\right)}{b_{1}\left(k_{e}^{2}+k_{r}^{2}\right)+2 b_{2} k_{e} k_{r}-2 \beta\left(b_{1}^{2}-b_{2}^{2}\right)}
\end{gathered}
$$

Let $\beta_{c d 1}=k_{e}\left(k_{r}+k_{e}\right) /\left[2\left(b_{1}-b_{2}\right)\right]$, then we know $\beta_{c d 1}>\beta_{1}$. Furthermore, given $\beta>\beta_{1}$, we find from Equation (A2) that $\partial p_{r}^{C D *} / \partial \alpha<0$ if $\beta_{1}<\beta \leq \beta_{c d 1}$, and that $\partial p_{r}^{C D *} / \partial \alpha>0$ if $\beta>\beta_{c d 1}$. Since $\beta>\beta_{1}$, we know $k_{r}\left(k_{r}+k_{e}\right)<2 \beta\left(b_{1}-b_{2}\right)$. According to Equation (A3), we further know $\partial p_{e}^{C D *} / \partial \alpha<0$. In addition, we know that $\partial r^{C D *} / \partial \alpha<0$ according to Equation (A4).

Proof of Proposition 2. According to Equations (5)-(7), we can obtain first order derivatives of optimal joint decision policy with respect to parameter $l$, i.e.,

$$
\begin{gathered}
\frac{\partial p_{r}^{C D *}}{\partial l}=\frac{k_{e}\left(b_{1} k_{r}+b_{2} k_{e}\right)}{2\left[b_{1}\left(k_{e}^{2}+k_{r}^{2}\right)+2 b_{2} k_{e} k_{r}-2 \beta\left(b_{1}^{2}-b_{2}^{2}\right)\right]} \\
\frac{\partial p_{e}^{C D *}}{\partial l}=\frac{b_{1}\left(2 k_{e}^{2}+k_{r}^{2}\right)+3 b_{2} k_{e} k_{r}-2 \beta\left(b_{1}^{2}-b_{2}^{2}\right)}{2\left[b_{1}\left(k_{e}^{2}+k_{r}^{2}\right)+2 b_{2} k_{e} k_{r}-2 \beta\left(b_{1}^{2}-b_{2}^{2}\right)\right]} \\
\frac{\partial r^{C D *}}{\partial l}=\frac{k_{e}\left(b_{1}^{2}-b_{2}^{2}\right)}{b_{1}\left(k_{e}^{2}+k_{r}^{2}\right)+2 b_{2} k_{e} k_{r}-2 \beta\left(b_{1}^{2}-b_{2}^{2}\right)}
\end{gathered}
$$


Let $\beta_{c d 2}=\left[b_{1}\left(2 k_{e}^{2}+k_{R}^{2}\right)+3 b_{2} k_{e} k_{r}\right] /\left[2\left(b_{1}^{2}-b_{2}^{2}\right)\right]$, then we know $\beta_{c d 2}>\beta_{1}$. Obviously, $\partial p_{e}^{C D *} / \partial l<0$ if $\beta_{1}<\beta \leq \beta_{c d 2}$, and $\partial p_{e}^{C D *} / \partial l>0$ if $\beta>\beta_{c d 2}$. In addition, according to Equations (A5) and (A7), we know $\partial p_{r}^{C D *} / \partial l<0$ and $\partial r^{C D *} / \partial l<0$.

Proof of Theorem 2. For Model B, we can determine Hessian matrix $H_{2}$ of $\pi_{M}\left(p_{e}, w, r\right)$ with respect to $w, p_{e}$, and $r$, i.e.,

$$
H_{2}=\left(\begin{array}{lll}
\frac{\partial^{2} \pi_{M}}{\partial p_{e}^{2}} & \frac{\partial^{2} \pi_{M}}{\partial p_{\partial} \partial w} & \frac{\partial^{2} \pi_{M}}{\partial p_{e} \partial r} \\
\frac{\partial^{2} \pi_{M}}{\partial w p_{e}} & \frac{\partial^{2} \pi_{M}}{\partial w^{2}} & \frac{\partial^{2} \pi_{M}}{\partial w \partial r} \\
\frac{\partial^{2} \pi_{M}}{\partial r \partial p_{e}} & \frac{\partial^{2} \pi_{M}}{\partial r \partial w} & \frac{\partial^{2} \pi_{M}}{\partial r^{2}}
\end{array}\right)=\left(\begin{array}{ccc}
-2 b_{1} & 2 b_{2} & k_{e} \\
2 b_{2} & -2 b_{1} & k_{r} \\
k_{e} & k_{r} & -\beta
\end{array}\right)
$$

Given $\beta>\beta_{1}$, we know that matrix $H_{2}$ is negative definite, and thus we know that $\pi_{M}\left(p_{e}, w, r\right)$ is a joint concave function with respect to $p_{e}, w$, and $r$. Furthermore, we can determine the response functions of manufacturer by $\partial \pi_{M} / \partial p_{e}=0, \partial \pi_{M} / \partial w=0$, and $\partial \pi_{M} / \partial r=0$, i.e.,

$$
\begin{gathered}
p_{e}=\frac{a k_{r}\left[(1-\alpha) k_{r}-\alpha k_{e}\right]+\left(b_{1} k_{e}+b_{2} k_{r}\right)\left[(c+t) k_{e}+(c+m) k_{r}\right]-2 a \beta\left[b_{1}(1-\alpha)+b_{2} \alpha\right]}{2\left[b_{1}\left(k_{e}^{2}+k_{r}^{2}\right)-2 \beta\left(b_{1}^{2}-b_{2}^{2}\right)+2 b_{2} k_{e} k_{r}\right]}+\frac{t+c}{2} \\
w=\frac{a k_{e}\left[\alpha k_{e}-(1-\alpha) k_{r}\right]+\left(b_{1} k_{r}+b_{2} k_{e}\right)\left[(c+t) k_{e}+(c+m) k_{r}\right]-2 a \beta\left[b_{2}(1-\alpha)+b_{1} \alpha\right]}{2\left[b_{1}\left(k_{e}^{2}+k_{r}^{2}\right)-2 \beta\left(b_{1}^{2}-b_{2}^{2}\right)+2 b_{2} k_{e} k_{r}\right]}+\frac{c-m}{2} \\
r=\frac{\left(b_{1}^{2}+b_{2}^{2}\right)\left[(c+t) k_{e}+(c+m) k_{r}\right]+a(1-\alpha)\left(b_{2} k_{r}-b_{1} k_{e}\right)-a \alpha\left(b_{1} k_{r}+b_{2} k_{e}\right)}{b_{1}\left(k_{e}^{2}+k_{r}^{2}\right)-2 \beta\left(b_{1}^{2}-b_{2}^{2}\right)+2 b_{2} k_{e} k_{r}}
\end{gathered}
$$

By substituting Equations (A9)-(A11) into profit function of retailer, we can obtain the converted retailer's profit function $\pi_{R}(m)$, then we can determine the second order derivative of $\pi_{R}(m)$ with respect to $m$, i.e.,

$$
\frac{\partial^{2} \pi_{R}}{\partial m^{2}}=-\frac{\left(b_{1} k_{e}+b_{2} k_{r}\right)^{2}-2 \beta b_{1}\left(b_{1}^{2}-b_{2}^{2}\right)}{2\left[b_{1}\left(k_{e}^{2}+k_{r}^{2}\right)+2 b_{2} k_{e} k_{r}-2 \beta\left(b_{1}^{2}-b_{2}^{2}\right)\right]}
$$

Since $\beta>\beta_{1}$, then we know $\left(b_{1} k_{e}+b_{2} k_{r}\right)^{2}<2 \beta b_{1}\left(b_{1}^{2}-b_{2}^{2}\right)$, and thus we know $\partial^{2} \pi_{R} / \partial m^{2}<0$. Obviously, $\pi_{R}$ is a concave function with respect to $m$. By $\partial \pi_{R} / \partial m=0$, we can obtain $m^{R S *}$. Then we can determine optimal joint decision policy of $p_{e}^{R S *}, w^{R S *}$, and $r^{R S *}$ by substituting $m^{R S *}$ into Equations (A9)-(A11).

Proof of Proposition 3. According to Equations (8)-(12), we can obtain first order derivatives of optimal joint decision policy with respect to parameter $\alpha$, i.e.,

$$
\begin{gathered}
\frac{\partial m^{R S *}}{\partial \alpha}=\frac{a\left[\left(b_{1} k_{e}+b_{2} k_{r}\right)\left(k_{e}+k_{r}\right)-2 \beta\left(b_{1}^{2}-b_{2}^{2}\right)\right]}{2\left[\left(b_{1} k_{e}+b_{2} k_{r}\right)^{2}-2 \beta b_{1}\left(b_{1}^{2}-b_{2}^{2}\right)\right]} \\
\frac{\partial w^{R S *}}{\partial \alpha}=\frac{a\left[k_{e}\left(k_{e}+k_{r}\right)-2 \beta\left(b_{1}-b_{2}\right)\right]}{4\left[b_{1}\left(k_{e}^{2}+k_{r}^{2}\right)+2 b_{2} k_{e} k_{r}-2 \beta\left(b_{1}^{2}-b_{2}^{2}\right)\right]}+\frac{a \beta b_{2}\left(b_{1}-b_{2}\right)}{2\left[\left(b_{1} k_{e}+b_{2} k_{r}\right)^{2}-2 \beta b_{1}\left(b_{1}^{2}-b_{2}^{2}\right)\right]} \\
\frac{\partial p_{r}^{R S *}}{\partial \alpha}=\frac{a\left[k_{e}\left(k_{e}+k_{r}\right)-2 \beta\left(b_{1}-b_{2}\right)\right]}{4\left[b_{1}\left(k_{e}^{2}+k_{r}^{2}\right)+2 b_{2} k_{e} k_{r}-2 \beta\left(b_{1}^{2}-b_{2}^{2}\right)\right]}+\frac{a\left[\left(b_{1} k_{e}+b_{2} k_{r}\right)\left(k_{e}+k_{r}\right)-\beta\left(b_{1}-b_{2}\right)\left(2 b_{1}+b_{2}\right)\right]}{2\left[\left(b_{1} k_{e}+b_{2} k_{r}\right)^{2}-2 \beta b_{1}\left(b_{1}^{2}-b_{2}^{2}\right)\right]} \\
\frac{a\left[k_{r}\left(b_{1} k_{e}+b_{2} k_{r}\right)-4 \beta b_{1}\left(b_{1}-b_{2}\right)\right]\left[b_{1}\left(k_{e}^{2}+k_{r}^{2}\right)+2 b_{2} k_{e} k_{r}-2 \beta\left(b_{1}^{2}-b_{2}^{2}\right)\right]}{\partial \alpha}=-\frac{+a k_{r}^{2}\left(b_{1}-b_{2}\right)\left(k_{e}-k_{r}\right)\left(b_{1} k_{e}+b_{2} k_{r}\right)}{4\left[\left(b_{1} k_{e}+b_{2} k_{r}\right)^{2}-2 \beta b_{1}\left(b_{1}^{2}-b_{2}^{2}\right)\right]\left[b_{1}\left(k_{e}^{2}+k_{r}^{2}\right)+2 b_{2} k_{e} k_{r}-2 \beta\left(b_{1}^{2}-b_{2}^{2}\right)\right]}
\end{gathered}
$$




$$
\frac{\partial r^{R S *}}{\partial \alpha}=\frac{a\left(b_{1}-b_{2}\right)\left(k_{e}-k_{r}\right)}{2\left[b_{1}\left(k_{e}^{2}+k_{r}^{2}\right)+2 b_{2} k_{e} k_{r}-2 \beta\left(b_{1}^{2}-b_{2}^{2}\right)\right]}+\frac{a\left(b_{1}-b_{2}\right)\left(b_{1} k_{e}+b_{2} k_{r}\right)}{2\left[\left(b_{1} k_{e}+b_{2} k_{r}\right)^{2}-2 \beta b_{1}\left(b_{1}^{2}-b_{2}^{2}\right)\right]}
$$

Let $\beta_{m r s 1}=\left(b_{1} k_{e}+b_{2} k_{r}\right)\left(k_{e}+k_{r}\right) /\left[2\left(b_{1}^{2}-b_{2}^{2}\right)\right]$, we know $\beta_{m r s 1}>\beta_{1}$ and $\beta>\beta_{1}$. According to Equation (A13), we know that $\partial m^{R S_{*}} / \partial m<0$ if $\beta_{1}<\beta \leq \beta_{m r s 1}$, and that $\partial m^{R S *} / \partial m>0$ if $\beta>\beta_{m r s 1}$. Let $Y_{w \alpha 1}=2 \beta b_{2}\left(b_{1}-b_{2}\right)\left[b_{1}\left(k_{e}^{2}+k_{r}^{2}\right)+2 b_{2} k_{e} k_{r}-2 \beta\left(b_{1}^{2}-b_{2}^{2}\right)\right]$ $+\left[\left(b_{1} k_{e}+b_{2} k_{r}\right)^{2}-2 \beta b_{1}\left(b_{1}^{2}-b_{2}^{2}\right)\right] \cdot\left[k_{e}\left(k_{e}+k_{r}\right)-2 \beta\left(b_{1}-b_{2}\right)\right]$. According to Equation (A14), we know that $\partial w^{R S *} / \partial \alpha>0$ if $Y_{w \alpha 1}>0$, and that $\partial w^{R S *} / \partial \alpha<0$ if $Y_{w \alpha 1} \leq 0$. Let $Y_{p r \alpha 1}=$ $2\left[b_{1}\left(k_{e}^{2}+k_{r}^{2}\right)+2 b_{2} k_{e} k_{r}-2 \beta\left(b_{1}^{2}-b_{2}^{2}\right)\right] \quad\left[\left(b_{1} k_{e}+b_{2} k_{r}\right)\left(k_{e}+k_{r}\right)-\beta\left(b_{1}-b_{2}\right)\left(2 b_{1}+b_{2}\right)\right]$ $+\left[\left(b_{1} k_{e}+b_{2} k_{r}\right)^{2}-2 \beta b_{1}\left(b_{1}^{2}-b_{2}^{2}\right)\right]\left[k_{e}\left(k_{e}+k_{r}\right)-2 \beta\left(b_{1}-b_{2}\right)\right]$. According to Equation (A15), we know that $\partial p_{r}^{R S *} / \partial \alpha>0$ if $Y_{p r \alpha 1}>0$, and that $\partial p_{r}^{R S *} / \partial \alpha<0$ if $Y_{p r \alpha 1} \leq 0$. In addition, given $\beta>\beta_{1}$, we know $k_{r}\left(b_{1} k_{e}+b_{2} k_{r}\right)<4 \beta b_{1}\left(b_{1}-b_{2}\right)$, and thus we further know $\partial p_{e}^{R S *} / \partial \alpha<0$ according to Equation (A16). Similarly, we know $\partial r^{R S *} / \partial \alpha<0$ according to Equation (A17).

Proof of Proposition 4. According to Equations (8)-(12), we can obtain first order derivatives of optimal joint decision policy with respect to parameter $l$, i.e.,

$$
\begin{gathered}
\frac{\partial m^{R S *}}{\partial l}=-\frac{k_{e} k_{r}\left(b_{1}^{2}+b_{2}^{2}\right)+b_{1} b_{2}\left(k_{e}^{2}+k_{r}^{2}\right)-2 \beta b_{2}\left(b_{1}^{2}-b_{2}^{2}\right)}{2\left[\left(b_{1} k_{e}+b_{2} k_{r}\right)^{2}-2 \beta b_{1}\left(b_{1}^{2}-b_{2}^{2}\right)\right]} \\
\frac{\partial w^{R S *}}{\partial l}=\frac{\left[k_{e}\left(b_{1} k_{e}+b_{2} k_{r}\right)-2 \beta\left(b_{1}^{2}-b_{2}^{2}\right)\right]\left[k_{e} k_{r}\left(b_{1}^{2}+b_{2}^{2}\right)+b_{1} b_{2}\left(k_{e}^{2}+k_{r}^{2}\right)-2 \beta b_{2}\left(b_{1}^{2}-b_{2}^{2}\right)\right]}{4\left[\left(b_{1} k_{e}+b_{2} k_{r}\right)^{2}-2 \beta b_{1}\left(b_{1}^{2}-b_{2}^{2}\right)\right]\left[b_{1}\left(k_{e}^{2}+k_{r}^{2}\right)+2 b_{2} k_{e} k_{r}-2 \beta\left(b_{1}^{2}-b_{2}^{2}\right)\right]} \\
\frac{\partial p_{r}^{R S *}}{\partial l}=-\frac{\left[\left(b_{1} k_{e}^{2}+3 b_{2} k_{e} k_{r}+2 b_{1} k_{r}^{2}\right)-2 \beta\left(b_{1}^{2}-b_{2}^{2}\right)\right]\left[k_{e} k_{r}\left(b_{1}^{2}+b_{2}^{2}\right)+b_{1} b_{2}\left(k_{e}^{2}+k_{r}^{2}\right)-2 \beta b_{2}\left(b_{1}^{2}-b_{2}^{2}\right)\right]}{4\left[\left(b_{1} k_{e}+b_{2} k_{r}\right)^{2}-2 \beta b_{1}\left(b_{1}^{2}-b_{2}^{2}\right)\right]\left[b_{1}\left(k_{e}^{2}+k_{r}^{2}\right)+2 b_{2} k_{e} k_{r}-2 \beta\left(b_{1}^{2}-b_{2}^{2}\right)\right]} \\
\frac{\partial p_{e}^{R S *}}{\partial l}=-\frac{k_{r}\left(b_{1} k_{e}+b_{2} k_{r}\right)\left[k_{e} k_{r}\left(b_{1}^{2}+b_{2}^{2}\right)+b_{1} b_{2}\left(k_{e}^{2}+k_{r}^{2}\right)-2 \beta b_{2}\left(b_{1}^{2}-b_{2}^{2}\right)\right]}{4\left[\left(b_{1} k_{e}+b_{2} k_{r}\right)^{2}-2 \beta b_{1}\left(b_{1}^{2}-b_{2}^{2}\right)\right]\left[b_{1}\left(k_{e}^{2}+k_{r}^{2}\right)+2 b_{2} k_{e} k_{r}-2 \beta\left(b_{1}^{2}-b_{2}^{2}\right)\right]} \\
\frac{\partial r R S *}{\partial l}=-\frac{k_{r}\left(b_{1}^{2}-b_{2}^{2}\right)\left[k_{e} k_{r}\left(b_{1}^{2}+b_{2}^{2}\right)+b_{1} b_{2}\left(k_{e}^{2}+k_{r}^{2}\right)-2 \beta b_{2}\left(b_{1}^{2}-b_{2}^{2}\right)\right]}{2\left[\left(b_{1} k_{e}+b_{2} k_{r}\right)^{2}-2 \beta b_{1}\left(b_{1}^{2}-b_{2}^{2}\right)\right]\left[b_{1}\left(k_{e}^{2}+k_{r}^{2}\right)+2 b_{2} k_{e} k_{r}-2 \beta\left(b_{1}^{2}-b_{2}^{2}\right)\right]}
\end{gathered}
$$

For $\beta>\beta_{1}$, we know $k_{e}\left(b_{1} k_{e}+b_{2} k_{r}\right)<2 \beta\left(b_{1}^{2}-b_{2}^{2}\right)$. Let $\beta_{r s}=\left[k_{e} k_{r}\left(b_{1}^{2}+b_{2}^{2}\right)+\right.$ $\left.b_{1} b_{2}\left(k_{e}^{2}+k_{r}^{2}\right)\right] /\left[2 b_{2}\left(b_{1}^{2}-b_{2}^{2}\right)\right]$, then we know $\beta_{r s}>\beta_{1}$. According to Equations (A18), (A19), (A21), and (A22), we know that, if $\beta_{1}<\beta \leq \beta_{r s}$, then $\partial m^{R S *} / \partial l>0, \partial w^{R S *} / \partial l<0$, $\partial p_{e}^{R S *} / \partial l<0$, and $\partial r^{R S *} / \partial l<0$; if $\beta>\beta_{r s}$, then $\partial m^{R S *} / \partial l<0, \partial w^{R S *} / \partial l>0, \partial p_{e}^{R S *} / \partial l>$ 0 , and $\partial r^{R S *} / \partial l>0$. In addition, let $\beta_{\text {prrs }}=\left(b_{1} k_{e}^{2}+3 b_{2} k_{e} k_{r}+2 b_{1} k_{r}^{2}\right) /\left[2\left(b_{1}^{2}-b_{2}^{2}\right)\right]$, we know $\beta_{\text {prrs }}>\beta_{1}$. According to Equation (A20), we know that $\partial p_{r}^{R S *} / \partial l<0$ if $\beta_{1}<\beta \leq \min \left\{\beta_{r s}, \beta_{\text {prrs }}\right\}$ or $\beta>\max \left\{\beta_{r s}, \beta_{\text {prrs }}\right\}$, and that $\partial p_{r}^{R S *} / \partial l>0$ if $\beta_{r s}<\beta \leq \beta_{\text {prrs }}$ or $\beta_{\text {prrs }}<\beta \leq \beta_{r s}$.

Proof of Proposition 5. According to Equations (8)-(12), we can obtain first order derivatives of optimal joint decision policy with respect to parameter $t$, i.e.,

$$
\begin{gathered}
\frac{\partial m^{R S *}}{\partial t}=\frac{k_{e} k_{r}\left(b_{1}^{2}+b_{2}^{2}\right)+b_{1} b_{2}\left(k_{e}^{2}+k_{r}^{2}\right)-2 \beta b_{2}\left(b_{1}^{2}-b_{2}^{2}\right)}{\left(b_{1} k_{e}+b_{2} k_{r}\right)^{2}-2 \beta b_{1}\left(b_{1}^{2}-b_{2}^{2}\right)} \\
\frac{\partial w^{R S *}}{\partial t}=\frac{\beta b_{2}\left(b_{1}^{2}-b_{2}^{2}\right)}{\left(b_{1} k_{e}+b_{2} k_{r}\right)^{2}-2 \beta b_{1}\left(b_{1}^{2}-b_{2}^{2}\right)} \\
\frac{\partial p_{r}^{R S *}}{\partial t}=\frac{k_{e} k_{r}\left(b_{1}^{2}+b_{2}^{2}\right)+b_{1} b_{2}\left(k_{e}^{2}+k_{r}^{2}\right)-\beta b_{2}\left(b_{1}^{2}-b_{2}^{2}\right)}{\left(b_{1} k_{e}+b_{2} k_{r}\right)^{2}-2 \beta b_{1}\left(b_{1}^{2}-b_{2}^{2}\right)}
\end{gathered}
$$




$$
\begin{gathered}
\frac{\partial p_{e}^{R S *}}{\partial t}=\frac{\left(b_{1} k_{e}+b_{2} k_{r}\right)^{2}-\beta b_{1}\left(b_{1}^{2}-b_{2}^{2}\right)}{b_{1}\left(k_{e}^{2}+k_{r}^{2}\right)+2 b_{2} k_{e} k_{r}-2 \beta\left(b_{1}^{2}-b_{2}^{2}\right)} \\
\frac{\partial r^{R S *}}{\partial t}=\frac{\left(b_{1}^{2}-b_{2}^{2}\right)\left(b_{1} k_{e}+b_{2} k_{r}\right)}{\left(b_{1} k_{e}+b_{2} k_{r}\right)^{2}-2 \beta b_{1}\left(b_{1}^{2}-b_{2}^{2}\right)}
\end{gathered}
$$

Let $\beta_{m r s 3}=\left[k_{e} k_{r}\left(b_{1}^{2}+b_{2}^{2}\right)+b_{1} b_{2}\left(k_{e}^{2}+k_{r}^{2}\right)\right] /\left[2 b_{2}\left(b_{1}^{2}-b_{2}^{2}\right)\right]$, we know $\beta_{1}<\beta_{m r s 3}$ and $\beta>$ $\beta_{1}$. According to Equation (A23), we know that $\partial m^{R S *} / \partial t<0$ if $\beta_{1}<\beta \leq \beta_{m r s 3}$, and that $\partial m^{R S *} / \partial t>0$ if $\beta>\beta_{m r s 3}$. Let $\beta_{\text {prrs } 3}=\left[k_{e} k_{r}\left(b_{1}^{2}+b_{2}^{2}\right)+b_{1} b_{2}\left(k_{e}^{2}+k_{r}^{2}\right)\right] /\left[b_{2}\left(b_{1}^{2}-b_{2}^{2}\right)\right]$, we know $\beta_{1}<\beta_{\text {prrs3 } 3}$ and $\beta>\beta_{1}$. According to Equation (A25), we know that $\partial p_{r}^{R S *} / \partial t<0$ if $\beta_{1}<\beta \leq \beta_{\text {prrs } 3}$, and that $\partial p_{r}^{R S *} / \partial t>0$ if $\beta>\beta_{\text {prrs } 3}$. Let $\beta_{\text {pers } 3}=\left(b_{1} k_{e}+b_{2} k_{r}\right)^{2} /\left[b_{1}\left(b_{1}^{2}-b_{2}^{2}\right)\right]$, we know $\beta_{1}<\beta_{\text {pers } 3}$ and $\beta>\beta_{1}$. According to Equation (A26), we know that $\partial p_{e}^{R S *} / \partial t<0$ if $\beta_{1}<\beta \leq \beta_{\text {pers } 3}$, and that $\partial p_{e}^{R S *} / \partial t>0$ if $\beta>\beta_{\text {pers } 3}$. In addition, according to Equations (A24) and (A27), we know $\partial w^{R S *} / \partial t<0$ and $\partial r^{R S *} / \partial t<0$.

Proof of Theorem 3. According to Model D, we know $\partial^{2} \pi_{R} / \partial m^{2}=-2 b_{1}<0$. By $\partial \pi_{R} / \partial m=0$, we can obtain the response function of retailer, i.e.,

$$
m=\frac{\alpha a-b_{1} w+k_{r} r+b_{2}\left(p_{e}-l+t\right)}{2 b_{1}}
$$

By substituting Equation (A28) into manufacturer's profit function, we can obtain the converted function $\pi_{M}\left(w, p_{e}, r\right)$. Then we can further obtain Hessian matrix $\mathrm{H}_{3}$ of $\pi_{M}\left(w, p_{e}, r\right)$ with respect to $w, p_{e}$, and $r$, i.e.,

$$
H_{3}=\left(\begin{array}{ccc}
\frac{\partial^{2} \pi_{M}}{\partial w^{2}} & \frac{\partial^{2} \pi_{M}}{\partial w \partial p_{e}} & \frac{\partial^{2} \pi_{M}}{\partial w \partial r} \\
\frac{\partial^{2} \pi_{M}}{\partial p_{e} \partial w} & \frac{\partial^{2} \pi_{M}}{\partial p_{e}^{2}} & \frac{\partial^{2} \pi_{M}}{\partial p_{e} \partial r} \\
\frac{\partial^{2} \pi_{M}}{\partial r \partial w} & \frac{\partial^{2} \pi_{M}}{\partial r \partial p_{e}} & \frac{\partial^{2} \pi_{M}}{\partial r^{2}}
\end{array}\right)=\left(\begin{array}{ccc}
-b_{1} & b_{2} & \frac{k_{r}}{2} \\
b_{2} & \frac{b_{2}{ }^{2}}{b_{1}}-2 b_{1} & k_{e}+\frac{b_{2} k_{r}}{2 b_{1}} \\
\frac{k_{r}}{2} & k_{e}+\frac{b_{2} k_{r}}{2 b_{1}} & -\beta
\end{array}\right)
$$

Given $\beta>\beta_{1}$, we know that matrix $H_{3}$ is negative definite. By $\partial \pi_{M} / \partial w=0$, $\partial \pi_{M} / \partial p_{e}=0$, and $\partial \pi_{M} / \partial r=0$, we can obtain $w^{M S *}, p_{e}^{M S *}$, and $r^{M S *}$. Furthermore, the optimal $m^{M S *}$ can be determined according to Equation (A28).

Proof of Proposition 6. According to Equations (13)-(17), we can obtain first order derivatives of optimal joint decision policy with respect to parameter $\alpha$, i.e.,

$$
\begin{gathered}
\frac{\partial m^{M S *}}{\partial \alpha}=\frac{\left[\left(b_{1} k_{e}+b_{2} k_{r}\right)\left(k_{r}+k_{e}\right)-2 \beta\left(b_{1}^{2}-b_{2}^{2}\right)\right] a}{2\left[\left(b_{1}^{2}+b_{2}^{2}\right) k_{r}^{2}+2 b_{1} k_{e}\left(b_{1} k_{e}+2 b_{2} k_{r}\right)-4 \beta b_{1}\left(b_{1}^{2}-b_{2}^{2}\right)\right]} \\
\frac{\partial w^{M S *}}{\partial \alpha}=\frac{\left[\left(2 b_{1} k_{e}+b_{2} k_{r}\right)\left(k_{r}+k_{e}\right)-4 \beta\left(b_{1}^{2}-b_{1} b_{2}\right)\right] a}{2\left[\left(b_{1}^{2}+b_{2}^{2}\right) k_{r}^{2}+2 b_{1} k_{e}\left(b_{1} k_{e}+2 b_{2} k_{r}\right)-4 \beta b_{1}\left(b_{1}^{2}-b_{2}^{2}\right)\right]} \\
\frac{\partial p_{r}^{M S *}}{\partial \alpha}=\frac{a\left[\left(3 b_{1} k_{e}+2 b_{2} k_{r}\right)\left(k_{r}+k_{e}\right)-2 \beta\left(3 b_{1}^{2}-2 b_{1} b_{2}-b_{2}^{2}\right)\right]}{2\left[\left(b_{1}^{2}+b_{2}^{2}\right) k_{r}^{2}+2 b_{1} k_{e}\left(b_{1} k_{e}+2 b_{2} k_{r}\right)-4 \beta b_{1}\left(b_{1}^{2}-b_{2}^{2}\right)\right]} \\
\frac{\partial p_{e}^{M S *}}{\partial \alpha}=-\frac{\left[k_{r}\left(k_{r}+k_{e}\right)-4 \beta\left(b_{1}-b_{2}\right)\right] b_{1} a}{2\left[\left(b_{1}^{2}+b_{2}^{2}\right) k_{r}^{2}+2 b_{1} k_{e}\left(b_{1} k_{e}+2 b_{2} k_{r}\right)-4 \beta b_{1}\left(b_{1}^{2}-b_{2}^{2}\right)\right]} \\
\frac{\partial r^{M S *}}{\partial \alpha}=\frac{\left.a\left(b_{1}-b_{2}\right)\left[b_{1}\left(2 k_{e}-k_{r}\right)+b_{2} k_{r}\right)\right]}{\left(b_{1}^{2}+b_{2}^{2}\right) k_{r}^{2}+2 b_{1} k_{e}\left(b_{1} k_{e}+2 b_{2} k_{r}\right)-4 \beta b_{1}\left(b_{1}^{2}-b_{2}^{2}\right)}<0
\end{gathered}
$$

Let $\beta_{m m s 1}=\left(b_{1} k_{e}+b_{2} k_{r}\right)\left(k_{r}+k_{e}\right) /\left[2\left(b_{1}^{2}-b_{2}^{2}\right)\right]$, then we know $\beta_{1}<\beta_{m m s 1}$ and $\beta>\beta_{1}$. According to Equation (A30), we know that $\partial m^{M S *} / \partial \alpha<0$ if $\beta_{1}<\beta \leq \beta_{m m s 1}$, and that $\partial m^{M S *} / \partial \alpha>0$ if $\beta>\beta_{m m s 1}$. Let $\beta_{w m s 1}=\left(2 b_{1} k_{e}+b_{2} k_{r}\right)\left(k_{r}+k_{e}\right) /\left[4\left(b_{1}^{2}-b_{1} b_{2}\right)\right]$, 
then we know $\beta_{1}<\beta_{w m s 1}$ and $\beta>\beta_{1}$. According to Equation (A31), we know that $\partial w^{M S *} / \partial \alpha<0$ if $\beta_{1}<\beta \leq \beta_{w m s 1}$, and that $\partial w^{M S *} / \partial \alpha>0$ if $\beta>\beta_{w m s 1}$. Let $\beta_{\text {prms } 1}=$ $\left(3 b_{1} k_{e}+2 b_{2} k_{r}\right)\left(k_{r}+k_{e}\right) /\left[2\left(3 b_{1}^{2}-2 b_{1} b_{2}-b_{2}^{2}\right)\right]$, then we know $\beta_{1}<\beta_{p r m s 1}$ and $\beta>\beta_{1}$. According to Equation (A32), we know that $\partial p_{r}^{M S *} / \partial \alpha<0$ if $\beta_{1}<\beta \leq \beta_{\text {prms } 1 \text {, and that }}$ $\partial p_{r}^{M S *} / \partial \alpha>0$ if $\beta>\beta_{p r m s 1}$. In addition, given $\beta>\beta_{1}$, we know $k_{r}\left(k_{r}+k_{e}\right)<4 \beta\left(b_{1}-b_{2}\right)$. According to Equations (A33) and (A34), we know that $\partial p_{e}^{M S *} / \partial \alpha<0$ and $\partial r^{M S *} / \partial \alpha<0$.

Proof of Proposition 7. According to Equations (13)-(17), we can determine first order derivatives of optimal joint decision policy with respect to parameter $l$, i.e.,

$$
\begin{gathered}
\frac{\partial m^{M S *}}{\partial l}=-\frac{b_{2}\left[\left(2 b_{1}^{2}+b_{2}^{2}\right) k_{r}^{2}+3 b_{1} k_{e}\left(b_{1} k_{e}+2 b_{2} k_{r}\right)-6 \beta b_{1}\left(b_{1}^{2}-b_{2}^{2}\right)\right]}{2 b_{1}\left[\left(b_{1}^{2}+b_{2}^{2}\right) k_{r}^{2}+2 b_{1} k_{e}\left(b_{1} k_{e}+2 b_{2} k_{r}\right)-4 \beta b_{1}\left(b_{1}^{2}-b_{2}^{2}\right)\right]} \\
\frac{\partial w^{M S *}}{\partial l}=\frac{b_{2}\left[\left(2 b_{1} k_{e}+b_{2} k_{r}\right)\left(b_{1} k_{e}+b_{2} k_{r}\right)-4 \beta b_{1}\left(b_{1}^{2}-b_{2}^{2}\right)\right]}{2 b_{1}\left[\left(b_{1}^{2}+b_{2}^{2}\right) k_{r}^{2}+2 b_{1} k_{e}\left(b_{1} k_{e}+2 b_{2} k_{r}\right)-4 \beta b_{1}\left(b_{1}^{2}-b_{2}^{2}\right)\right]} \\
\frac{\partial p_{r}^{M S *}}{\partial l}=-\frac{b_{2}\left[b_{1}\left(2 k_{r}^{2}+k_{e}^{2}\right)+3 b_{2} k_{r} k_{e}-2 \beta\left(b_{1}^{2}-b_{2}^{2}\right)\right]}{2\left[\left(b_{1}^{2}+b_{2}^{2}\right) k_{r}^{2}+2 b_{1} k_{e}\left(b_{1} k_{e}+2 b_{2} k_{r}\right)-4 \beta b_{1}\left(b_{1}^{2}-b_{2}^{2}\right)\right]} \\
\frac{\partial p_{e}^{M S *}}{\partial l}=-\frac{b_{2} k_{r}\left(b_{1} k_{e}+b_{2} k_{r}\right)}{2\left[\left(b_{1}^{2}+b_{2}^{2}\right) k_{r}^{2}+2 b_{1} k_{e}\left(b_{1} k_{e}+2 b_{2} k_{r}\right)-4 \beta b_{1}\left(b_{1}^{2}-b_{2}^{2}\right)\right]}>0 \\
\frac{\partial r^{M S *}}{\partial l}=-\frac{b_{2} k_{r}\left(b_{1}^{2}-b_{2}^{2}\right)}{\left(b_{1}^{2}+b_{2}^{2}\right) k_{r}^{2}+2 b_{1} k_{e}\left(b_{1} k_{e}+2 b_{2} k_{r}\right)-4 \beta b_{1}\left(b_{1}^{2}-b_{2}^{2}\right)}>0
\end{gathered}
$$

Obviously, according to Equations (A38) and (A39), we know that $\partial p_{e}^{M S *} / \partial l>0$ and $\partial r^{M S *} / \partial l>0$. Since $\beta>\beta_{1}$, we know that $\left(2 b_{1}{ }^{2}+b_{2}{ }^{2}\right) k_{r}{ }^{2}+3 b_{1} k_{e}\left(b_{1} k_{e}+2 b_{2} k_{r}\right)<$ $6 \beta b_{1}\left(b_{1}{ }^{2}-b_{2}^{2}\right)$, according to Equation (A35), we further know that $\partial m^{M S *} / \partial l<0$. In addition, for $\beta>\beta_{1}$, we can also know that $\left(2 b_{1} k_{e}+b_{2} k_{r}\right)\left(b_{1} k_{e}+b_{2} k_{r}\right)<4 \beta b_{1}\left(b_{1}^{2}-b_{2}^{2}\right)$, according to Equation (A36), we further know that $\partial w^{M S *} / \partial l>0$. Let $\beta_{\text {prms2 }}$ $=\left[b_{1}\left(2 k_{r}^{2}+k_{e}^{2}\right)+3 b_{2} k_{r} k_{e}\right] /\left[2\left(b_{1}^{2}-b_{2}^{2}\right)\right]$, then we know that $\beta_{1}<\beta_{p r m s 2}$ and $\beta>\beta_{1}$. According to Equation (A37), we further know that $\partial p_{r}^{M S *} / \partial l>0$ if $\beta_{1}<\beta \leq \beta_{\text {prms } 2}$, and that $\partial p_{r}^{M S *} / \partial l<0$ if $\beta>\beta_{m m s 2}$.

Proof of Proposition 8. According to Equations (13)-(17), we can determine first order derivatives of optimal joint decision policy with respect to parameter $t$, i.e.,

$$
\begin{aligned}
& \frac{\partial m^{M S *}}{\partial t}=\frac{\left(b_{1}^{2}+7 b_{2}^{2}\right) b_{1} k_{e} k_{r}+b_{1}{ }^{2} b_{2}\left(3 k_{r}^{2}+4 k_{e}{ }^{2}\right)+b_{2}{ }^{3} k_{r}{ }^{2}-8 \beta b_{1} b_{2}\left(b_{1}^{2}-b_{2}{ }^{2}\right)}{2 b_{1}\left[\left(b_{1}{ }^{2}+b_{2}^{2}\right) k_{r}{ }^{2}+2 b_{1} k_{e}\left(b_{1} k_{e}+2 b_{2} k_{r}\right)-4 \beta b_{1}\left(b_{1}{ }^{2}-b_{2}{ }^{2}\right)\right]} \\
& \frac{\partial w^{M S *}}{\partial t}=\frac{\left(b_{1}^{2}-b_{2}^{2}\right)\left[k_{r}\left(2 b_{1} k_{e}+b_{2} k_{r}\right)+4 \beta b_{1} b_{2}\right]}{2 b_{1}\left[\left(b_{1}^{2}+b_{2}^{2}\right) k_{r}^{2}+2 b_{1} k_{e}\left(b_{1} k_{e}+2 b_{2} k_{r}\right)-4 \beta b_{1}\left(b_{1}^{2}-b_{2}^{2}\right)\right]}<0 \\
& \frac{\partial p_{r}^{M S}}{\partial t}=\frac{4 b_{1} b_{2}\left(k_{r}^{2}+k_{e}^{2}\right)+k_{r} k_{e}\left(3 b_{1}^{2}+5 b_{2}^{2}\right)-4 \beta b_{2}\left(b_{1}^{2}-b_{2}^{2}\right)}{2\left[\left(b_{1}^{2}+b_{2}^{2}\right) k_{r}^{2}+2 b_{1} k_{e}\left(b_{1} k_{e}+2 b_{2} k_{r}\right)-4 \beta b_{1}\left(b_{1}^{2}-b_{2}^{2}\right)\right]} \\
& \frac{\partial p_{e}^{M S *}}{\partial t}=\frac{4\left(b_{1} k_{e}+b_{2} k_{r}\right)^{2}+\left(b_{1}^{2}-b_{2}^{2}\right) k_{r}^{2}-4 \beta b_{1}\left(b_{1}^{2}-b_{2}^{2}\right)}{2\left[\left(b_{1}^{2}+b_{2}^{2}\right) k_{r}^{2}+2 b_{1} k_{e}\left(b_{1} k_{e}+2 b_{2} k_{r}\right)-4 \beta b_{1}\left(b_{1}^{2}-b_{2}^{2}\right)\right]} \\
& \frac{\partial r^{M S *}}{\partial t}=\frac{2\left(b_{1}^{2}-b_{2}^{2}\right)\left(b_{1} k_{e}+b_{2} k_{r}\right)}{\left(b_{1}^{2}+b_{2}^{2}\right) k_{r}^{2}+2 b_{1} k_{e}\left(b_{1} k_{e}+2 b_{2} k_{r}\right)-4 \beta b_{1}\left(b_{1}^{2}-b_{2}^{2}\right)}<0
\end{aligned}
$$

Obviously, according to Equations (A41) and (A44), we know that $\partial w^{M S *} / \partial t<$ 0 and $\partial r^{M S *} / \partial t<0$. Let $\beta_{m m s 3}=\left[\left(b_{1}{ }^{2}+7 b_{2}{ }^{2}\right) b_{1} k_{e} k_{r}+b_{1}{ }^{2} b_{2}\left(3 k_{r}{ }^{2}+4 k_{e}{ }^{2}\right)+b_{2}{ }^{3} k_{r}{ }^{2}\right] /$ $\left[8 b_{1} b_{2}\left(b_{1}{ }^{2}-b_{2}^{2}\right)\right]$, then we know that $\beta_{1}<\beta_{m m s 3}$ and $\beta>\beta_{1}$. According to Equation (A40), we further know that $\partial m^{M S *} / \partial t<0$ if $\beta_{1}<\beta \leq \beta_{m m s 3}$, and that $\partial m^{M S *} / \partial t>0$ if $\beta>\beta_{m m s 3}$. Let $\beta_{\text {prms } 3}=\left[4 b_{1} b_{2}\left(k_{r}^{2}+k_{e}^{2}\right)+k_{r} k_{e}\left(3 b_{1}^{2}+5 b_{2}^{2}\right)\right] /\left[4 b_{2}\left(b_{1}^{2}-b_{2}^{2}\right)\right]$, then 
we know that $\beta_{1}<\beta_{\text {prms3 }}$ and $\beta>\beta_{1}$. According to Equation (A42), we further know that $\partial p_{r}^{M S *} / \partial t<0$ if $\beta_{1}<\beta \leq \beta_{p r m s 3}$, and that $\partial p_{r}^{M S *} / \partial t>0$ if $\beta>\beta_{p r m s 3}$. Let $\beta_{\text {pems } 3}=\left[4\left(b_{1} k_{e}+b_{2} k_{r}\right)^{2}+\left(b_{1}{ }^{2}-b_{2}{ }^{2}\right) k_{r}{ }^{2}\right] /\left[4 b_{1}\left(b_{1}{ }^{2}-b_{2}{ }^{2}\right)\right]$, then we know that $\beta_{1}<$ $\beta_{\text {pems3 } 3}$ and $\beta>\beta_{1}$. According to Equation (A43), we further know that $\partial p_{e}^{M S *} / \partial t<0$ if $\beta_{1}<\beta \leq \beta_{\text {pems3 }}$, and that $\partial p_{e}^{M S *} / \partial t>0$ if $\beta>\beta_{\text {pems } 3}$.

Proof of Theorem 4. According to Model $D$, by $\partial \pi_{M}^{R C} / \partial w=0$, we can obtain

$$
w=\frac{c b_{1}-b_{2}(c+t)-(1+2 \lambda) b_{1} m+b_{2} p_{e}(2+\lambda)}{2 b_{1}(1+\lambda)}+\frac{a \alpha+r k_{r}}{2 b_{1}}
$$

Furthermore, let $p_{e}^{R C *}=p_{e}^{C D *}, r^{R C *}=r^{C D *}$, and $p_{r}^{R C *}=p_{r}^{C D *}$, then according to $p_{r}^{R C *}=w^{R C *}+m^{R C *}$, we can determine

$$
m^{R C *}=\frac{\left\{2 c \lambda b_{1}-b_{2}[(2+\lambda) l-2 t+c \lambda]\right\}\left[2 \beta\left(b_{1}^{2}-b_{2}^{2}\right)-b_{1}\left(k_{e}^{2}+k_{r}^{2}\right)-2 b_{2} k_{e} k_{r}\right]}{-\lambda b_{2}\left\{(c+l) b_{1} k_{e}^{2}+\left[(1-\alpha) a+c b_{2}\right] k_{r}^{2}-k_{e} k_{r}\left[a \alpha-c b_{1}-(c+l) b_{2}\right]-2 a \beta\left[(1-\alpha) b_{1}+\alpha b_{2}\right]\right\}}
$$

By substituting Equation (A46) into Equation (A45), we can determine $w^{R C *}$.

Proof of Theorem 5. According to Model E, by $\partial \pi_{R}^{M C} / \partial m=0$, we can obtain

$$
m=\frac{(1-\gamma)\left(\alpha a+k_{r} r\right)+b_{2}\left[(1-\gamma) p_{e}-l+t\right]+b_{1}(2 \gamma-1) w}{2(1-\gamma) b_{1}}
$$

Let $r^{M C *}=r^{C D *}, p_{e}^{M C *}=p_{e}^{C D *}$, and $p_{r}^{M C *}=p_{r}^{C D *}$, then we can obtain $w^{M C *}$ according to $p_{r}^{M C *}=w^{M C *}+m^{M C *}$ and Equation (A47).

\section{References}

1. Kraus, S.; Rehman, S.; Sendra-Garcia, F. Corporate social responsibility and environmental performance: The mediating role of environmental strategy and green innovation. Technol. Forecast. Soc. 2020, 160, 120262. [CrossRef]

2. $\mathrm{Wu}, \mathrm{H}$.; Li, G.; Xiao, S.; Li, H. Technology driven alliance for environmental and social responsibility in power supply chains. J. Clean. Prod. 2020, 276, 23194. [CrossRef]

3. Wu, W.; Zhang, Q.; Liang, Z. Environmentally responsible closed-loop supply chain models for joint environmental responsibility investment, recycling and pricing decisions. J. Clean. Prod. 2020, 259, 120776. [CrossRef]

4. Song, X.; Lu, Y.; Shen, L.; Shi, X. Will China's building sector participate in emission trading system? Insights from modelling an owner's optimal carbon reduction strategies. Energ. Policy 2018, 118, 232-244. [CrossRef]

5. Song, X.; Shen, M.; Lu, Y.; Shen, L.; Zhang, H. How to effectively guide carbon reduction behavior of building owners under emission trading scheme? An evolutionary game-based study. Environ. Impact Asses. 2021, 90, 106624. [CrossRef]

6. Stekelorum, R.; Laguir, I.; ElBaz, J. Can you hear the Eco? From SME environmental responsibility to social requirements in the supply chain. Technol. Forecast. Soc. 2020, 158, 120169. [CrossRef]

7. Xia, J.; Niu, W. Carbon-reducing contract design for a supply chain with environmental responsibility under asymmetric information. Omega 2021, 102, 102390. [CrossRef]

8. Li, Y.; Xiong, Y.; Mariuzzo, F.; Xia, S. The underexplored impacts of online consumer reviews: Pricing and new product design strategies in the O2O supply chain. Int. J. Prod. Econ. 2021, 237, 108148. [CrossRef]

9. Pei, Z.; Wooldridge, B.; Swimberghe, K. Manufacturer rebate and channel coordination in O2O retailing. J. Retail. Consum. Serv. 2021, 58, 102268. [CrossRef]

10. Yan, R.; Cao, Z. Product returns, asymmetric information, and firm performance. Int. J. Prod. Econ. 2017, 185, 211-222. [CrossRef]

11. Yan, R.; Pei, Z.; Ghose, S. Reward points, profit sharing, and valuable coordination mechanism in the $\mathrm{O} 2 \mathrm{O}$ era. Int. J. Prod. Econ. 2019, 215, 34-47. [CrossRef]

12. $\mathrm{Wu}, \mathrm{Y}$.; Lu, R.; Yang, J.; $\mathrm{Xu}$, F. Low-carbon decision-making model of online shopping supply chain considering the $\mathrm{O} 2 \mathrm{O}$ model. J. Retail. Consum. Serv. 2021, 59, 102388. [CrossRef]

13. Wu, Y.; Lu, R.; Yang, J.; Wang, R.; Xu, H.; Jiang, C. Government-led low carbon incentive model of the online shopping supply chain considering the $\mathrm{O} 2 \mathrm{O}$ model. J. Clean. Prod. 2021, 279, 123271. [CrossRef]

14. Zhao, F.; Wu, D.; Liang, L.; Dolgui, A. Lateral inventory transshipment problem in online-to-offline supply chain. Int. J. Prod. Res. 2016, 54, 1951-1963. [CrossRef] 
15. Nakandala, D.; Lau, H.; Zhang, J. Strategic hybrid lateral transshipment for cost-optimized inventory management. Ind. Manag. Data. Syst. 2016, 117, 1632-1649. [CrossRef]

16. Nakandala, D.; Lau, H.; Shum, P. A lateral transshipment model for perishable inventory management. Int. J. Prod. Res. 2017, 55, 5341-5354. [CrossRef]

17. Chen, X.; Wang, X.; Jiang, X. The impact of power structure on the retail service supply chain with an O2O mixed channel. J. Oper. Res. Soc. 2016, 67, 294-301. [CrossRef]

18. Kong, L.; Liu, Z.; Pan, Y.; Xie, J.; Yang, G. Pricing and service decision of dual-channel operations in an O2O closed-loop supply chain. Ind. Manag. Data Syst. 2017, 117, 1567-1588. [CrossRef]

19. He, P.; He, Y.; Xu, H.; Zhou, L. Online selling mode choice and pricing in an $\mathrm{O} 2 \mathrm{O}$ tourism supply chain considering corporate social responsibility. Electron. Commer. Res. Appl. 2019, 38, 100894. [CrossRef]

20. Sarkar, B.; Ullah, M.; Choi, S. Joint inventory and pricing policy for an online to offline closed-loop supply chain model with random defective rate and returnable transport items. Mathematics 2019, 7, 497. [CrossRef]

21. Zheng, Y.; Liu, L.; Shi, V.; Liu, B.; Huang, W. Price cap models in pharmaceutical online-to-offline supply chains. Complexity 2020, 2020, 7471948. [CrossRef]

22. Chai, L.; Duan, Y.; Huo, Z. Pricing strategies for $\mathrm{O} 2 \mathrm{O}$ business model considering service spillover and power structures. Int. T. Oper. Res. 2021, 28, 1978-2001. [CrossRef]

23. Yu, X.; Wang, S.; Zhang, X. Ordering decision and coordination of a dual-channel supply chain with fairness concerns under an online-to-offline model. Asia Pac. J. Oper. Res. 2019, 36, 1940004. [CrossRef]

24. He, Y.; Zhang, J.; Gou, Q.; Bi, G. Supply chain decisions with reference quality effect under the O2O environment. Ann. Oper. Res. 2018, 268, 273-292. [CrossRef]

25. Yan, Y.; Zhao, R.; Liu, Z. Strategic introduction of the marketplace channel under spillovers from online to offline sales. Eur. J. Oper. Res. 2018, 267, 65-77. [CrossRef]

26. Zend, F.; Yaghoubi, S.; Sadjadi, S. Impacts of government direct limitation on pricing, greening activities and recycling management in an online to offline closed loop supply chain. J. Clean. Prod. 2019, 215, 1327-1340. [CrossRef]

27. Ma, D.; Hu, J.; Wang, W. Differential game of product-service supply chain considering consumers' reference effect and supply chain members' reciprocity altruism in the online-to-offline mode. Ann. Oper. Res. 2021, 304, 263-297. [CrossRef]

28. Ma, D.; Hu, J.; Yao, F. Big data empowering low-carbon smart tourism study on low-carbon tourism O2O supply chain considering consumer behaviors and corporate altruistic preferences. Comput. Ind. Eng. 2021, 153, 107061. [CrossRef]

29. Sarkar, B.; Dey, B.; Sarkar, M.; AlArjani, A. A sustainable online-to-offline (O2O) retailing strategy for a supply chain management under controllable lead time and variable demand. Sustainability 2021, 13, 1756. [CrossRef]

30. Sett, B.; Dey, B.; Sarkar, B. The effect of O2O retail service quality in supply chain management. Mathematics 2020, 8, 1743. [CrossRef]

31. Xu, Q.; Fu, G.; Fan, D. Service sharing, profit mode and coordination mechanism in the Online-to-Offline retail market. Econ Model. 2020, 91, 659-669. [CrossRef]

32. Sun, C.; Ye, L.; Zhang, N. O2O selection mode portrait and optimization for railway service enterprises based on K-means. Complex Intell. Syst. 2021. Available online: https:/ / doi.org/10.1007/s40747-021-00375-0 (accessed on 10 October 2021).

33. Melacini, M.; Perotti, S.; Rasini, M.; Tappia, E. E-fulfilment and distribution in omni-channel retailing: A systematic literature review. Int. J. Phys. Distr. Log. 2018, 48, 391-414. [CrossRef]

34. Cai, Y.; Lo, C. Omni-channel management in the new retailing era: A systematic review and future research agenda. Int. J. Prod. Econ. 2020, 229, 107729. [CrossRef]

35. Jiang, Y.; Liu, L.; Lim, A. Optimal pricing decisions for an omni-channel supply chain with retail service. Int. T. Oper. Res. 2020, 27, 2927-2948. [CrossRef]

36. Liu, L.; Feng, L.; Xu, B.; Deng, W. Operation strategies for an omni-channel supply chain: Who is better off taking on the online channel and offline service. Electron. Commer. Res. Appl. 2020, 39, 100918. [CrossRef]

37. Wu, J.; Zhao, C.; Yan, X.; Wang, L. An integrated randomized pricing strategy for omni-channel retailing. Int. J. Electron. Comm. 2020, 24, 391-418. [CrossRef]

38. Li, M.; Zhang, X.; Dan, B. Cooperative advertising and pricing in an $\mathrm{O} 2 \mathrm{O}$ supply chain with buy-online-and-pick-up-in-store. Int. T. Oper. Res. 2021, 28, 2033-2054. [CrossRef]

39. Chen, Z.; Su, S. Consignment supply chain cooperation for complementary products under online to offline business mode. Flex. Serv. Manuf. J. 2021, 33, 136-182. [CrossRef]

40. Karray, S.; Sigue, S. Offline retailers expanding online to compete with manufacturers: Strategies and channel power. Ind. Market. Manag. 2018, 71, 203-214. [CrossRef]

41. Sarkar, B.; Tayyab, M.; Choi, S. Product channeling in an $\mathrm{O} 2 \mathrm{O}$ supply chain management as power transmission in electric power distribution systems. Mathematics 2019, 7, 4. [CrossRef]

42. Wen, D.; Xiao, T.; Dastani, M. Pricing and collection rate decisions in a closed-loop supply chain considering consumers' environmental responsibility. J. Clean. Prod. 2020, 262, 121272. [CrossRef]

43. Yuan, X.; Tang, F.; Zhang, D.; Zhang, X. Green remanufacturer's mixed collection channel strategy considering enterprise's environmental responsibility and the fairness concern in reverse green supply chain. Int. J. Env. Res. Pub. He. 2021, 18, 3405. [CrossRef] [PubMed] 
44. Hong, Z.; Guo, X. Green product supply chain contracts considering environmental responsibilities. Omega 2019, 83, 155-166. [CrossRef]

45. Heydari, J.; Rafiei, P. Integration of environmental and social responsibilities in managing supply chains: A mathematical modeling approach. Comput. Ind. Eng. 2020, 145, 106495. [CrossRef]

46. Xie, L.; Ma, J.; Goh, M. Supply chain coordination in the presence of uncertain yield and demand. Int. J. Prod. Res. 2021, 59, 4342-4358. [CrossRef]

47. Heydari, J.; Govindan, K.; Basiri, Z. Balancing price and green quality in presence of consumer environmental awareness: A green supply chain coordination approach. Int. J. Prod. Res. 2021, 59, 1957-1975. [CrossRef]

48. Lee, J.; Kim, Y.; Kim, Y. Antecedents of adopting corporate environmental responsibility and green practices. J. Bus. Ethics. 2018, 148, 397-409. [CrossRef]

49. Yang, D.; Xiao, T.; Huang, J. Dual-channel structure choice of an environmental responsibility supply chain with green investment. J. Clean. Prod. 2019, 210, 134-145. [CrossRef]

50. Wu, Y.; Wang, J.; Li, C.; Su, K. Optimal supply chain structural choice under horizontal chain-to-chain competition. Sustainability 2018, 10, 1330. [CrossRef]

51. Carbone, V.; Moatti, V.; Schoenherr, T.; Gavirneni, S. From green to good supply chains: Halo effect between environmental and social responsibility. Int. J. Phys. Distr. Log. 2019, 49, 839-860. [CrossRef]

52. Qin, Y.; Harrison, J.; Chen, L. A framework for the practice of corporate environmental responsibility in China. J. Clean. Prod. 2019, 235, 426-452. [CrossRef]

53. Plambeck, E.; Taylor, T. Supplier evasion of a buyer's audit: Implications for motivating supplier social and environmental responsibility. MESOM Manuf. Serv. Op. 2016, 18, 184-197.

54. Dey, P.; Petridis, N.; Petridis, K.; Malesios, C.; Nixon, J.; Ghosh, S. Environmental management and corporate social responsibility practices of small and medium-sized enterprises. J. Clean. Prod. 2018, 195, 687-702. [CrossRef]

55. Kogg, B.; Mont, O. Environmental and social responsibility in supply chains: The practise of choice and inter-organisational management. Ecol. Econ. 2012, 83, 154-163. [CrossRef]

56. Kovacs, C. Corporate environmental responsibility in the supply chain. J. Clean. Prod. 2008, 16, 1571-1578. [CrossRef]

57. Villena, V.; Wilhelm, M.; Xiao, C. Untangling drivers for supplier environmental and social responsibility: An investigation in Philips Lighting's Chinese supply chain. J. Oper. Manag. 2021, 67, 476-510. [CrossRef]

58. Tuczek, F.; Castka, P.; Wakolbinger, T. A review of management theories in the context of quality, environmental and social responsibility voluntary standards. J. Clean. Prod. 2018, 176, 399-416. [CrossRef]

59. Herer, Y.; Rashit, A. Lateral stock transshipments in a two-location inventory system with fixed and joint replenishment costs. Nav. Res. Log. 1999, 46, 525-547. [CrossRef]

60. Firouz, M.; Keskin, B.; Melouk, S. An integrated supplier selection and inventory problem with multi-sourcing and lateral transshipments. Omega 2016, 70,77-93. [CrossRef]

61. Meissner, J.; Senicheva, O. Approximate dynamic programming for lateral transshipment problems in multi-location inventory systems. Eur. J. Oper. Res. 2017, 265, 49-64. [CrossRef]

62. Grahovac, J.; Chakravarty, A. Sharing and lateral transshipment of inventory in a supply chain with expensive low-demand items. Manag. Sci. 2001, 47, 579-594. [CrossRef]

63. Shokouhifar, M.; Sabbaghi, M.; Pilevari, N. Inventory management in blood supply chain considering fuzzy supply/demand uncertainties and lateral transshipment. Transfus. Apher. Sci. 2021, 60, 103103. [CrossRef] [PubMed]

64. Naseraldin, H.; Herer, Y. A location-inventory model with lateral transshipments. Nav. Res. Log. 2011, 58, 437-456. [CrossRef]

65. Yang, G.; Dekker, R.; Gabor, F.; Axsater, S. Service parts inventory control with lateral transshipment and pipeline stock flexibility. Int. J. Prod. Res. 2012, 142, 278-289. [CrossRef]

66. Paterson, C.; Kiesmuller, G.; Teunter, R.; Glazebrook, K. Inventory models with lateral transshipments: A review. Eur. J. Oper. Res. 2011, 210, 125-136. [CrossRef]

67. Gilbert, S.; Cvsa, V. Strategic commitment to price to stimulate downstream innovation in a supply chain. Eur. J. Oper. Res. 2003, 150, 617-639. [CrossRef]

68. Savaskan, R.; Bhattacharya, S.; Van-Wassenhove, L. Closed-loop supply chain models with product remanufacturing. Manag. Sci. 2004, 50, 239-252. [CrossRef]

69. Li, T.; Tan, Q.; Liu, W. Game theoretical perspectives on pricing decisions in asymmetric competing supply chains. Discret. Dyn. Nat. Soc. 2020, 2020, 9352013. [CrossRef]

70. Cao, B.; Gong, Z.; You, T. Stackelberg pricing policy in dyadic capital-constrained supply chain considering bank's deposit and loan based on delay payment scheme. J. Ind. Manag. Optim. 2021, 17, 2855-2887.

71. Huang, S.; Fan, Z.P.; Wang, N. Green subsidy modes and pricing strategy in a capital-constrained supply chain. Transp. Res. Part E Logisy. Transp. Rev. 2020, 136, 101885. [CrossRef]

72. Taleizadeh, A.; Sanezerang, E.; Choi, T. The effect of marketing effort on dual-channel closed-loop supply chain systems. IEEE Trans. Syst. Man Cybern. Syst. 2018, 48, 265-276. [CrossRef]

73. Taleizadeh, A.; Hazarkhani, B.; Moon, L. Joint pricing and inventory decisions with carbon emission considerations, partial backordering and planned discounts. Ann. Oper. Res. 2020, 290, 95-113. [CrossRef] 
74. Tsendsuren, C.; Yadav, R.; Han, S.; Kim, H. Influence of product market competition and managerial competency on corporate environmental responsibility: Evidence from the US. J. Clean. Prod. 2021, 304, 127065. [CrossRef]

75. Taleizadeh, A.; Cheraghi, Z.; Cardenas-Barron, L.; Noori-Daryan, M. Studying the effect of noise on pricing and marketing decisions of new products under co-op advertising strategy in supply chains: Game theoretical approaches. Mathematics 2021, 9 , 1222. [CrossRef]

76. Cao, B.; Fan, Z.; You, T. The optimal pricing and ordering policy for temperature sensitive products considering the effects of temperature on demand. J. Ind. Manag. Optim. 2019, 15, 1153-1184. [CrossRef]

77. Zhu, Q.; Li, X.; Zhao, S. Cost-sharing models for green product production and marketing in a food supply chain. Ind. Manag. Data Syst. 2018, 118, 654-682. [CrossRef]

78. Phan, D.; Vo, T.; Lai, A.; Nguyen, T. Coordinating contracts for VMI systems under manufacturer-CSR and retailer-marketing efforts. Int. J. Prod. Econ. 2019, 211, 98-118. [CrossRef]

79. Cao, B.; Fan, Z. Ordering and sales effort investment for temperature sensitive products considering retailer's disappointment aversion and elation seeking. Int. J. Prod. Res. 2018, 56, 2411-2436. [CrossRef]

80. Liu, Y.; Li, J.; Quan, B.; Yang, J. Decision analysis and coordination of two-stage supply chain considering cost information asymmetry of corporate social responsibility. J. Clean. Prod. 2019, 228, 1073-1087. [CrossRef]

81. Lou, G.; Lai, Z.; Ma, H.; Fan, T. Coordination in a composite green-product supply chain under different power structures. Ind. Manag. Data Syst. 2020, 120, 1101-1123. [CrossRef]

82. Shang, W.; Yang, L. Contract negotiation and risk preferences in dual-channel supply chain coordination. Int. J. Prod. Res. 2015, 53, 4837-4856. [CrossRef] 